\title{
Different techniques for the production of biodiesel from waste vegetable oil
}

\author{
*A. A. Refaat \\ Department of Chemical Engineering, Faculty of Engineering, Cairo University, Egypt
}

Received 13 October 2009; $\quad$ revised 8 November 2009; accepted 20 November 2009; available online 1 December 2009

\begin{abstract}
The production of biodiesel from waste vegetable oil offers a triple-facet solution: economic, environmental and waste management. The new process technologies developed during the last years made it possible to produce biodiesel from recycled frying oils comparable in quality to that of virgin vegetable oil biodiesel with an added attractive advantage of being lower in price. Thus, biodiesel produced from recycled frying oils has the same possibilities to be utilized. While transesterification is well-established and becoming increasingly important, there remains considerable inefficiencies in existing transesterification processes. There is an imperative need to improve the existing biodiesel production methods from both economic and environmental viewpoints and to investigate alternative and innovative production processes. This study highlights the main changes occurring in the oil during frying in order to identify the characteristics of oil after frying and the anticipated effects of the products formed in the frying process on biodiesel quality and attempts to review the different techniques used in the production of biodiesel from recycled oils, stressing the advantages and limitations of each technique and the optimization conditions for each process. The emerging technologies which can be utilized in this field are also investigated. The quality of biodiesel produced from waste vegetable oil in previous studies is also reviewed and the performance of engines fueled with this biodiesel and the characteristics of the exhaust emissions resulting from it are highlighted. The overarching goal is to stimulate further activities in the field.
\end{abstract}

Keywords: Engine performance; Exhaust emissions; Innovative technologies; Production optimization; Transesterification; Waste utilization

\section{INTRODUCTION}

The term "waste vegetable oil" (WVO) refers to vegetable oil which has been used in food production and which is no longer viable for its intended use. Waste vegetable oil arises from many different sources, including domestic, commercial and industrial. Waste vegetable oil is a potentially problematic waste stream which requires to be properly managed. The disposal of waste vegetable oil can be problematic when disposed, incorrectly, down kitchen sinks, where it can quickly cause blockages of sewer pipes when the oil solidifies. Properties of degraded used frying oil after it gets into sewage system are conductive to corrosion of metal and concrete elements. It also affects installations in waste water treatment plants. Thus, it adds to the cost of treating effluent or pollutes

*Corresponding Author Email: aarefaat@hotmail.com Tel./Fax: +20 122277897 waterways (Szmigielski et al., 2008). Biodiesel is a renewable, biodegradable, environmentally benign, energy efficient, substitution fuel which can fulfill energy security needs without sacrificing engine's operational performance. Thus, it provides a feasible solution to the twin crises of fossil fuel depletion and environmental degradation.

Any fatty acid source may be used to prepare biodiesel. Thus, any animal or plant lipid should be a ready substrate for the production of biodiesel. The use of edible vegetable oils and animal fats for biodiesel production has recently been of great concern because they compete with food materials - the food versus fuel dispute (Pimentel et al., 2009; Srinivasan, 2009). There are concerns that biodiesel feedstock may compete with food supply in the long-term (Lam et al., 2009; Metzger, 2009). Hence, the recent focus is the 
use of non-edible plant oil source and waste products of edible oil industry as the feedstock for biodiesel production meeting the international standards.

Quality standards are prerequisites for the commercial use of any fuel product. Since the implementation of the European standard specification EN 14214 in 2004, a standardized definition for biodiesel has been agreed as fatty acid methyl esters (FAME) from any kind of feedstock, including recycled frying oils, under fulfilling the given quality specifications. Thus, biodiesel produced from recycled frying oils has the same possibilities to be utilized. The new process technologies developed during the last years made it possible to produce biodiesel from recycled frying oils comparable in quality to that of virgin vegetable oil biodiesel with an added attractive advantage of being lower in price (Canakci, 2007; Chhetri et al., 2008; Refaat et al., 2008a).

From an economic point of view; the production of biodiesel is very feedstock sensitive. Many previous reports estimated the cost of biodiesel production based on assumptions, made by their authors, regarding production volume, feedstock and chemical technology (Canakci and van Gerpen, 2001; Zhang et al., 2003b; Kulkarni and Dalai, 2006). In all these reports, feedstock cost comprises a very substantial portion of overall biodiesel cost. Haas et al. (2006) developed a computer model to estimate the capital and operating costs of a moderately-sized industrial biodiesel production facility. Calculated production costs included the cost of the feedstock and of its conversion to biodiesel. Process economics included the recovery of co-product glycerol generated during biodiesel production and its sale The model is flexible in that it can be modified to calculate the effects on capital and production costs of changes in feedstock cost, changes in the type of feedstock employed, changes in the value of the glycerol co-product and changes in process chemistry and technology. The authors reported that for biodiesel produced from soybean oil, the cost of the oil feedstock accounted for $88 \%$ of total estimated production costs (Haas et al., 2006). Marchetti et al. (2008) used a conceptual design of alternative production plants with a techno-economic analysis in order to compare these alternatives. In all cases, more than $80 \%$ of the production cost is associated with the feedstock itself and consequently, efforts should be focused on developing technologies capable of using lower-cost feedstock, such as recycled cooking oils. Reusing of these waste greases can not only reduce the burden of the government in disposing the waste, maintaining public sewers and treating the oily wastewater, but also lower the production cost of biodiesel significantly.

From a waste management standpoint, producing biodiesel from used frying oil is environmentally beneficial, since it provides a cleaner way for disposing these products; meanwhile, it can yield valuable cuts in $\mathrm{CO}_{2}$ as well as significant tail-pipe pollution gains. $\mathrm{CO}_{2}$ is the main contributor of global warming and climate change through the enhanced (Tschakert et al., 2008). Relative to the fossil fuels they displace, greenhouse gas emissions are reduced $41 \%$ by the production and combustion of biodiesel (Hill et al., 2006). Biodiesel from used frying oil leads to a far better life cycle analysis. It has to be realized, that the effect of $\mathrm{CO}_{2}$ saving is significantly higher when using used frying oil as feedstock, because here the effects of the agricultural production of vegetable oils is not taken into consideration. In many researches WVO biodiesel showed net energy ratio (NER) of 5-6 compared to 2-3 for rapeseed or soybean biodiesel and 0.8 for petrodiesel (Rutz and Janssen, 2008). The NER is evaluated by dividing the energy output of the system by the cumulative energy demand of the system. Furthermore the processing of used frying oil into biodiesel is an ideal alternative to the use as animal feed (Supple et al., 2002), which is restricted by the law in Europe. The product therefore has the other benefits of being removed from the food chain. Limiting factor is the limited availability of used cooking oil on the market. Oil collection from household, commercial or industrial sources can be achieved through grease traps (Wong et al., 2007) or through a holistic policy framework (El Sheltawy and Refaat, 2009). Industries are adopting more energy-efficient technologies to improve its profitability and competitiveness (Tehrani et al., 2009).

This study highlights the main changes occurring in the oil during frying in order to identify the characteristics of oil after frying and the anticipated effects of the products formed in the frying process on biodiesel quality and attempts to review the different techniques used in the production of biodiesel from recycled oils, stressing the advantages and limitations of each technique and the optimization conditions for each process. The emerging technologies which can be utilized in this field are also investigated. The quality of biodiesel produced from waste vegetable oil in previous studies is also reviewed, together with the performance of engines fueled with this biodiesel and the characteristics of the exhaust emissions resulting from it. 
Identifying the characteristics of used frying oils

Used frying oils from restaurants and food industries have a wide variety of qualities. During the frying process, the oil is exposed to high temperatures in the presence of air and moisture. Under these conditions, it may undergo important changes due to hydrolytic, oxidative and thermal reactions. Changes in the main fat constituents are known, although it is not easy to foresee the rate of oil degradation due to the high number of variables involved in the frying process. Some of them are linked to the process itself, such as temperature, duration of heating, heating pattern (continuous or intermittent), turnover rate, etc.; others to the food subjected to frying, i.e. lipid composition, main and minor constituents, etc.; or else to the oil used e.g., degree of unsaturation, initial quality and additives (Rodrigues Machado et al., 2007). Thus, used frying oils can be highly heterogeneous as compared to crude or refined oils.

The new products formed during frying are polymers, dimers, oxidized triglycerides, as well as diglycerides and fatty acids. All these groups possess higher polarity than that corresponding to the initial triglycerides and can be easily quantified by means of adsorption chromatography (Ruiz-Méndez et al., 2008). The determination of polar fatty acids in biodiesels allows for the exact determination of non-polar esters and is an interesting alternative to the GC standard method due to its accuracy and to the fact that no instrumental techniques are required. From the percentage of polar compounds in used frying oils, the percentage of non-polar and polar methyl esters after the production of biodiesel can be roughly deduced given the excellent correlation between both determinations (Ruiz-Méndez et al., 2008).

Used frying oils can be analyzed by adsorption and size exclusion chromatography before and after transesterification for non-polar and polar species formed during frying. The determination of polar compounds by adsorption chromatography is the most accepted method for the analysis of used frying oils due to its high precision and accuracy. However, this method is expensive and time consuming. In a study conducted by Marmesat et al. (2007a), a rapid analytical method to determine polar compounds is proposed. Starting from milligrams of sample dissolved in a solution of hexane containing methyl oleate as internal standard, the non-polar fraction, which comprises the non-altered triglycerides (TG) and the internal standard, is obtained by solid phase extraction. Then, the non-polar fraction is quantitatively analyzed in $15 \mathrm{~min}$ by high-performance size-exclusion chromatography (HPSEC) and the polar fraction is determined by difference of weight. In another study Marmesat et al. (2007b), pointed out that the tests based on physical properties showed better results than those based on chemical reactions, as the number of false results was lower. Furthermore, they can be useful to gain information on the changes in the frying oil quality, as their results showed high correlation coefficients with the determination of polar compounds. Amore recent study by Lima et al. (2008) used Fourier Transform Infrared Photoacoustic Spectroscopy (FTIR-PAS) in identifying or monitoring spectral changes induced in the vegetable oils due to a degradation effect. Besides, the method can be used to contribute to the biodiesel wash process to separate the glycerol from the biodiesel. The authors argued that the method is efficient, fast and exhibits some advantages when compared with conventional processes, such as attenuated total reflectance (ATR).

Some key parameters were selected for determining the viability of the vegetable oil transesterification process. These parameters include: acid value and FFA content, moisture content, viscosity and fatty acid profile of the used oil. Knothe and Steidley (2009) preferred to determine the dynamic viscosity rather than the kinematic viscosity because of non-Newtonian behavior of some samples. The usual trend for the oils after frying was found to be an increase in the acid value, an increase in viscosity and an altered fatty acid profile (Knothe and Steidley, 2009). Fatty acid profile of the oil is an important determinant for the properties of the biodiesel produced. It was shown that the properties of the various fatty esters are determined by the structural features of the fatty acid and the alcohol moieties that comprise a fatty ester (Refaat, 2009). In a study conducted by Szmigielski, Maniak et al. (2008) to assess the usability of used frying rapeseed oil as a substrate for biofuel production it was shown that utilization of used frying rapeseed oil as fuel seems to be justified when favorable ratio of saturated and unsaturated fatty acids in oil fraction, and that this property stabilizes as a result of surface contact with potato chips (Szmigielski et al., 2008). A further study by the same authors on frying sunflower oil confirmed the previous findings (Maniak et al., 2009). In both studies, it was also shown that the acid value has 
increased after frying. In both studies it was also shown that the acid value has increased after frying. However, the increase in acid value was more prominent in the oil heated without the presence of potato chips (as shown in Figs. 1 and 2). These results were attributed to the water fraction introduced into oil with potato chips) and from absorption of hydrolysis products on porous surface of potatoes, as it was suggested that the key factor affecting changes of the investigated oil are oxidation transformations.

Thus, it can be concluded that the identification of some key parameters (acid value and free fatty acids (FFA) content, moisture content, viscosity and fatty acid profile of the used oil) is a prerequisite for determining the viability of the vegetable oil transesterification process and is essential to identify the right processes that can be performed to achieve best results with the yield and purity of the produced biodiesel, as will be shown, in details, in the following sections.

\section{Base-catalyzed transesterification}

Transesterification is the general term used to describe the important class of organic reactions where an ester is transformed into another through interchange of the alkoxy moiety (Freedman et al., 1986). Base-catalyzed transesterification involves stripping the glycerin from the fatty acids with a catalyst such as sodium or potassium hydroxide and replacing it with an anhydrous alcohol, usually methanol. The resulting

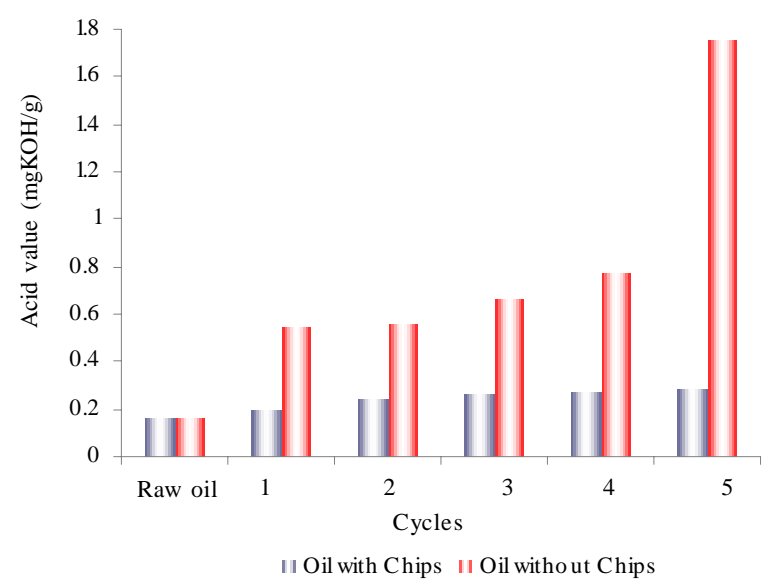

Fig. $\square$ Acid value of rapeseed oil subjected to cyclic heating (mg KOH/g) with and without potato chips (Szmigielski et al., 2008) raw product is then centrifuged and washed with water to cleanse it of impurities. This yields methyl or ethyl ester (biodiesel), as well as a smaller amount of glycerol, a valuable by-product used in making soaps, cosmetics and numerous other products.

Fig. 3 shows the process flow sheet of biodiesel production using the conventional mechanical method for base-catalyzed transesterification.

Base-catalyzed transesterification is the most commonly used technique as it is the most economical process since it requires only low temperatures and pressures; produces over $98 \%$ conversion yield (provided the starting oil is low in moisture and FFA) and involves direct conversion to biodiesel with no intermediate compounds; also, no special materials of construction are needed (Singh et al, 2006).

Base-catalyzed transesterification, however, has some limitations among which are that it is sensitive to FFA content of the feedstock oils. A high FFA content $(>1 \% \mathrm{w} / \mathrm{w}$ ) will lead to soap formation which reduces catalyst efficiency, causes an increase in viscosity, leads to gel formation and makes the separation of glycerol difficult. Also, the oils used in transesterification should be substantially anhydrous $(0.06 \% \mathrm{w} / \mathrm{w})$. The presence of water gives rise to hydrolysis of some of the produced ester, with consequent soap formation (Leung and Guo, 2006). Other drawbacks of the base-catalyzed transesterification is that the process is energy intensive, recovery of glycerol is difficult, alkaline

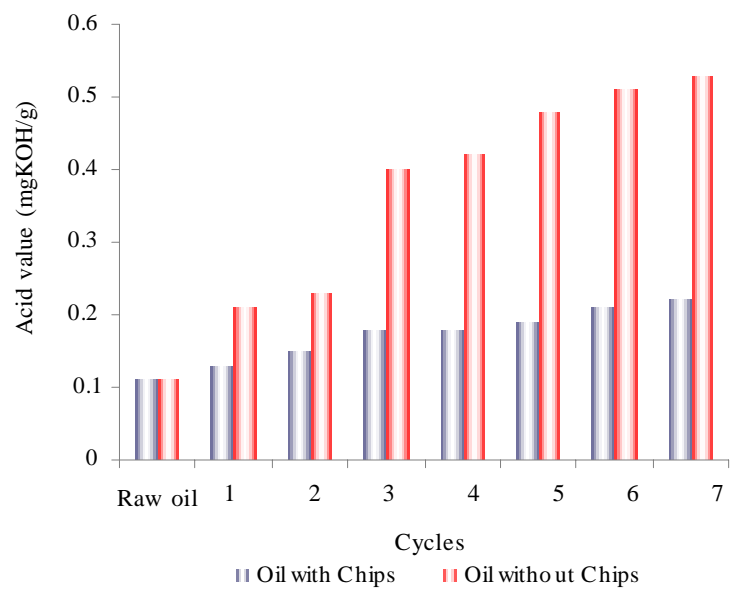

Fig. 2听id value of sunflower oil subjected to cyclic heating (mg KOH/g) with and without potato chips (Maniak et al., 2009) 


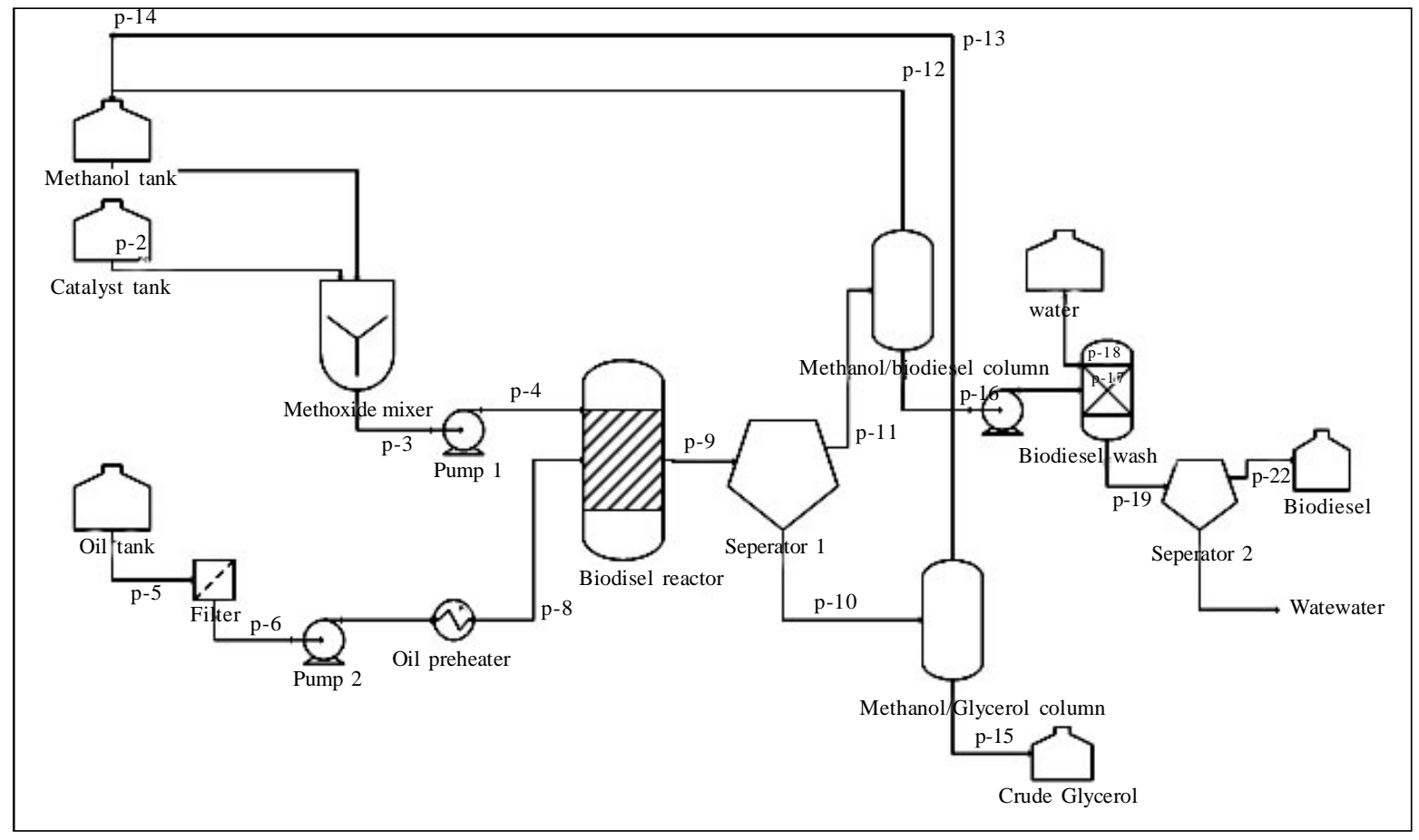

Fig. 3: Base-catalyzed transesterification process flow sheet

catalyst has to be removed from the product and alkaline waste water requires treatment (Meher et al., 2006).

\section{Pretreatment processes}

The negative effects of the undesirable compounds formed during the frying process can be avoided by different types of pretreatment before performing the base-catalyzed transesterification. These processes include filtration for removing suspended solids, maintaining the oil relatively dry by heating, suitable absorption/adsorption technique or sometimes by performing film vacuum evaporation or vacuum filtration. Other processes include: neutralization, steam injection and column chromatography.

To ensure an anhydrous medium the filtered oil can be subjected to drying by heating it to $100^{\circ} \mathrm{C}$ for at least 15 min with continuous stirring (Sudhir et al., 2007). In an earlier study by Felizardo et al. (2006), the authors performed pretreatment by drying the oil sample over magnesium sulphate followed by filtration under vacuum to remove any suspended matter and magnesium sulphate crystals. The authors mentioned that moisture removal at industrial scale is usually done by vacuum distillation ( 0.05 bar) at temperature range of $30-40^{\circ} \mathrm{C}$.
If the FFA content exceeds $1 \%$ and if an alkaline catalyst must be used, then a greater amount of catalyst should be added to neutralize the FFA (Kulkarni and Dalai, 2006). However, the correct amount of catalyst should be used because both excess as well as insufficient amount of catalyst may cause soap formation. To determine the correct amount of catalyst required, a titration must be performed on the oil being transesterified. One simple method was presented by Sudhir et al. (2007) in which phenolphthalein indicator is used. In the titration, $0.1 \%$ of $\mathrm{NaOH}$ in distilled water is titrated against the titration sample which is essentially a solution of $10 \mathrm{~mL}$ of Isopropyl alcohol and $1 \mathrm{~mL}$ of oil sample with 2-3 drops of indicator. The end point of the titration is marked when the titration sample turns pink (magenta) and stays pink for $10 \mathrm{~s}$. The number of milliliters of $0.1 \% \mathrm{NaOH}$ solution needed is equal to the number of extra grams of pure sodium hydroxide catalyst needed to produce the proper reaction to make biodiesel from WVO.

Supple et al. (2002) investigated the effect of steam injection and sedimentation treatment of waste cooking oil on the quality of TG to be used as a raw material for the production of biodiesel. The effect of steam 
treatment was evaluated in terms of a number of physical and chemical characteristics. Significant decreases in the moisture, FFA and PV, as well as increased energy value, were observed. GC analysis of the treated materials demonstrated little change in either the overall composition of the oils or the iodine value. The decreases in moisture from 1.4 to $0.4 \%$ and in FFA from 6.27 to $4.28 \%$ were found to correlate strongly with an increase in yield of ester from 67.5 to $83.5 \%$.

Cvengros and Cvengrosova (2004), however, outlined the general processes of WVO treatment that consists of a sequence of pretreatment methods to reduce the FFA, water and polymer content in the oil. FFA was removed by neutralization with alkalis $(\mathrm{KOH}$ or $\mathrm{NaOH}$ ) and separated as soaps in the decanter while high polymer content was treated with activated charcoal and removed by adsorption. Film vacuum evaporation was found to be more suitable for deacidification and drying. While drying was performed under moderate conditions of $159^{\circ} \mathrm{C}$ and 20 mbar, deacidification required more severe conditions of 200$280{ }^{\circ} \mathrm{C}$ and $0.1-8$ mbar. The reported yield of methyl ester obtained from the treated oil was $96 \%$.

Other pretreatment methods have been reported in literature: In an attempt to regenerate restaurant grease before esterification by removing excess FFA, Lee et al. (2002) carried out filtration and column chromatography. Cooking oil containing $10.6 \%$ FFA and $0.2 \%$ water was purified by passing it through a mixture of $50 \%$ aluminum oxide and $50 \%$ magnesium silicate. The FFA and water contents decreased from $10.6 \%$ to $0.23 \%$ and from $0.2 \%$ to 0.02 wt \%, respectively. The conversion of untreated oil before column chromatography was observed to have increased from $25 \%$ to $96 \%$ when pretreated oil was used. Saifuddin and Chua (2004) used filtration and drying by using microwave oven at $60^{\circ} \mathrm{C}$ for 10 minutes. Issariyakul et al. (2007) carried out pretreatment by centrifugation to remove solid portion of the oil. Water was removed by mixing the oil with $10 \mathrm{wt} \%$ silica gel (28-200 mesh) followed by stirring and vacuum filtration. Yuan et al. (2008) employed distillation as refining technique for reduction of FFA content in WVO. Dias et al. (2008) employed filtration under vacuum after dehydration over night using anhydrous sulfate and finally filtered the oil again under vacuum prior to transesterification. Predojevic (2008) pretreated the oil by drying over calcium chloride and filtered through cellulose filter to remove any suspended matter and calcium chloride crystals. Ozbay et al. (2008) carried out a successful venture to reduce the amount of FFA through esterification of WVO using ion exchange resins and reported that acidic ion exchange resins (Amberlyst15(A-15), Amberlyst-35 (A-35), Amberlyst-16 (A-16) and Dowex HCR-W2) can be used to decrease the FFA level of waste cooking oil (WCO).

Parameters affecting base-catalyzed Whansesterification

The main parameters affecting the base-catalyzed transesterification process are: alcohol formulation, alcohol/oil molar ratio, catalyst formulation and concentration, reaction temperature, reaction time, agitation, and the presence of moisture and FFA.

\section{Alcohol formulation}

Short-chain alcohols such as methanol, ethanol and butanol are the most frequently employed. Although the use of different alcohols presents some differences with regard to the reaction kinetics, the final yield of esters remains more or less inalterable. Therefore, selection of the alcohol is based on cost and performance consideration (Encinar et al., 2007).

Methanol was dominating in most of the literature reviewed (Alcantara et al., 2000; Encinar et al., 2005; Felizardo et al., 2006; Refaat et al., 2008a; Yuan et al., 2008). Methyl, rather than ethyl, ester production was modeled because methyl esters are the predominant commercial products, methanol is considerably cheaper and more available than ethanol (Pinto et al., 2005) and the downstream recovery of unreacted alcohol is much easier (Zhou and Boocock, 2006).

Ethanol maintains its capability of being renewable as an advantage. It can be produced from agricultural renewable resources, thereby attaining total independence from petroleum-based alcohols (Saifuddin and Chua, 2004; Encinar et al., 2007). In addition to the entirely agricultural nature of the ethanol, the extra carbon atom brought by the ethanol molecule slightly increases the heat content and the cetane number. Also, ethanol, as extraction solvent, is preferable to methanol because of its much higher dissolving power for oils. Finally, another important advantage in the use of ethanol is that the ethyl esters have cloud and pour points that are lower than the methyl esters (Encinar et al., 2007). However, the utilization of ethanol also presents inconveniences. The base-catalyzed formation of ethyl ester is difficult compared to the formation of methyl esters; reaction 
rate with ethanol is slightly slower than with methanol, what is attributed to the more difficult formation of the ethoxide anion (Om Tapanes et al., 2008). Also, the formation of stable emulsion during ethanolysis is a problem. Methanol and ethanol are not miscible with triglycerides at room temperature and the reaction mixture is usually mechanically stirred to enhance mass transfer. During the curse of reaction, emulsions are usually formed. In the case of methanolysis, these emulsions break down quickly and easily to form a lower glycerol rich layer and upper methyl ester rich layer. In ethanolysis, these emulsions are more stable and severely complicate the separation and purification of esters (Zhou and Boocock, 2006; Encinar et al., 2007).

\section{Molar ratio of alcohol to triglyceride}

One of the most important variables affecting the yield of ester is the molar ratio of alcohol to triglyceride. The stoichiometric ratio for transesterification requires three moles of alcohol and one mole of triglyceride to yield three moles of fatty acid alkyl esters and one mole of glycerol. However, transesterification is an equilibrium reaction in which an excess of alcohol is required to drive the reaction to the right ( $\mathrm{Ma}$ and Hanna, 1999). However, an excessive amount of alcohol makes the recovery of the glycerol difficult, so that the ideal alcohol/oil ratio has to be established empirically (Schuchardt et al., 1998).

For maximum conversion to the ester, a molar ratio of $6: 1$ is the most acceptable. Most of the studies on the base-catalyzed transesterification of WVO reported that maximum conversion to the ester occurred with a molar ratio of 6:1 (Tomasevic and Siler-Marinkovic, 2003; Saifuddin and Chua, 2004; Encinar et al., 2005; Gupta et al., 2007; Meng et al., 2008; Refaat et al., 2008b). Transesterification of pretreated waste rapeseed oil carried out by Yuan et al. (2008) showed a maximum conversion at $6.5: 1$ of methanol to oil ratio, whereas an earlier study by Leung and Guo (2006) found a maximum conversion at a ratio of $7: 1$. With further increase in molar ratio the conversion efficiency more or less remains the same (Fig. 4) but the energy required for the recovery of methanol becomes higher (Demirbas, 2009).

\section{Catalyst formulation}

Among the most commonly used alkaline catalysts in the biodiesel industry are potassium hydroxide $(\mathrm{KOH})$ and sodium hydroxide $(\mathrm{NaOH})$ flakes which are inexpensive and easy to handle in transportation and storage. They are preferred by small producers. Alkyl oxide solutions of sodium methoxide or potassium methoxide in methanol, which are now commercially available, are the preferred catalysts for large continuousflow production processes (Singh et al., 2006).

Biodiesel with the best properties was obtained using potassium hydroxide as catalyst in many studies (Tomasevic and Siler-Marinkovic, 2003; Encinar et al., 2005; Encinar et al., 2007; Gupta et al., 2007; Refaat et al., 2008a; Demirbas, 2009). Besides, many other studies achieved best results using $\mathrm{NaOH}$ (Saifuddin
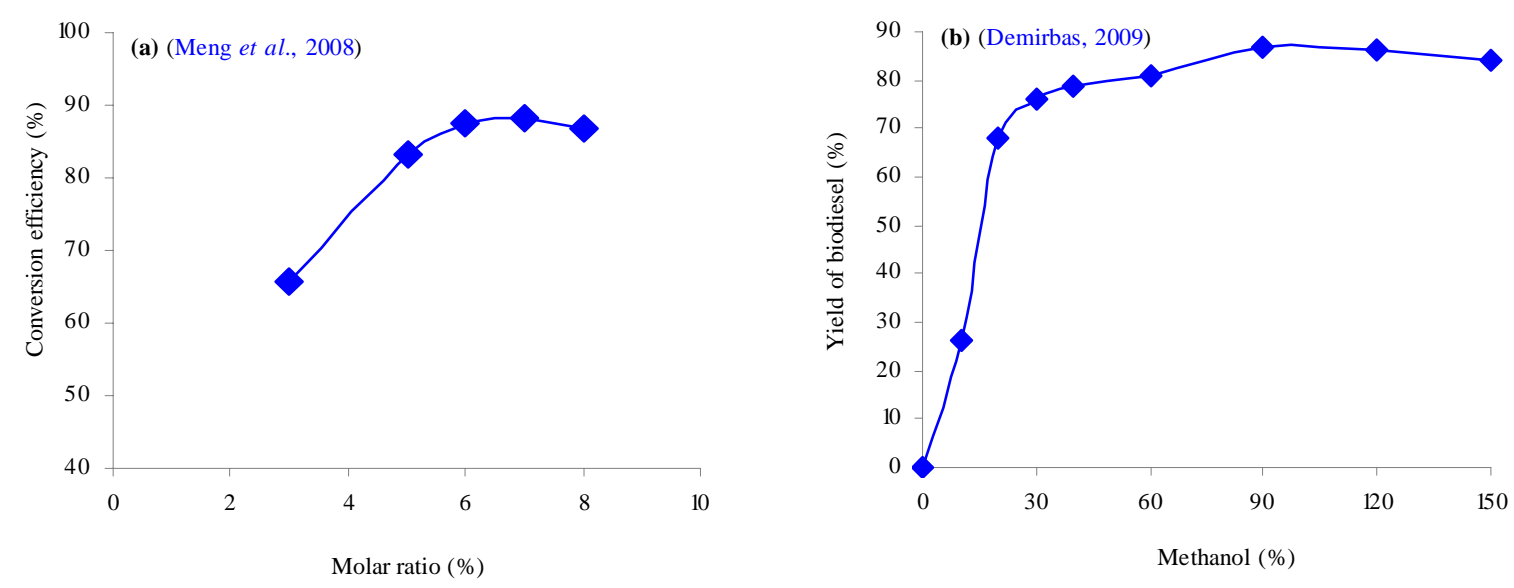

Fig. 4: Effect of methanol to oil molar ratio on the transesterification of WVO 
and Chua, 2004; Felizardo, et al., 2006; Leung and Guo, 2006; Chetri et al., 2008; Meng et al., 2008).

Encinar et al. (2007) studied the influence of catalyst type on the evolution of esters yield with time and found that potassium catalyst presented the best behavior and also observed that the hydroxides gave rise to higher percentages than the corresponding methoxides (Fig. 5).

These results are very similar to those found in the literature in transesterification processes of used frying oil with methanol and other alcohols, that also concluded that potassium hydroxide was the best catalyst (Tomasevic and Siler-Marinkovic, 2003; Dorado et al., 2004; Refaat et al., 2008a).

\section{Catalyst concentration}

In the case of the alkaline catalysis, the literature presents many works relating to this issue. In most of the literature reviewed the results showed that the bestsuited catalyst concentrations giving the best yields and viscosities of the esters are between 0.5 and $1.0 \mathrm{wt}$ $\%$. For higher values the yields were lower.

Catalyst concentration is closely related to the free acidity of the oil. When there is a large free fatty acid content, the addition of more potassium hydroxide, or any other alkaline catalyst, compensates this acidity and avoids catalyst deactivation (Freedman et al., 1986). The addition of an excessive amount of catalyst, however, gives rise to the formation of an emulsion,

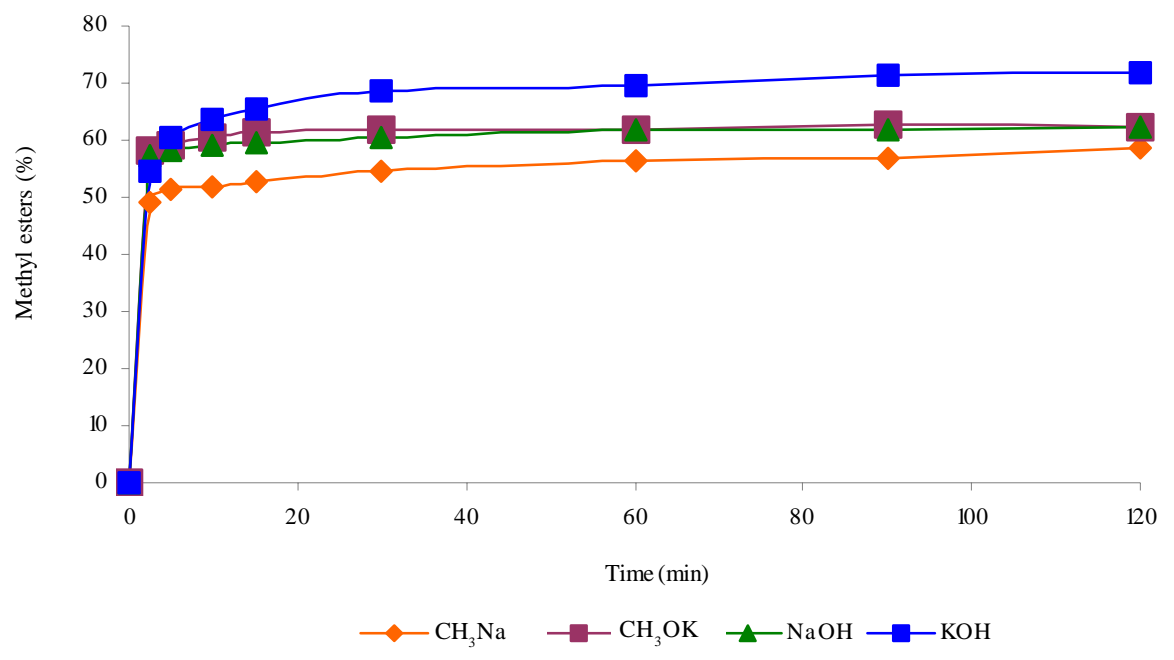

Fig. 5: Esters yield vs. time. Influence of catalyst type (Encinar et al., 2007)

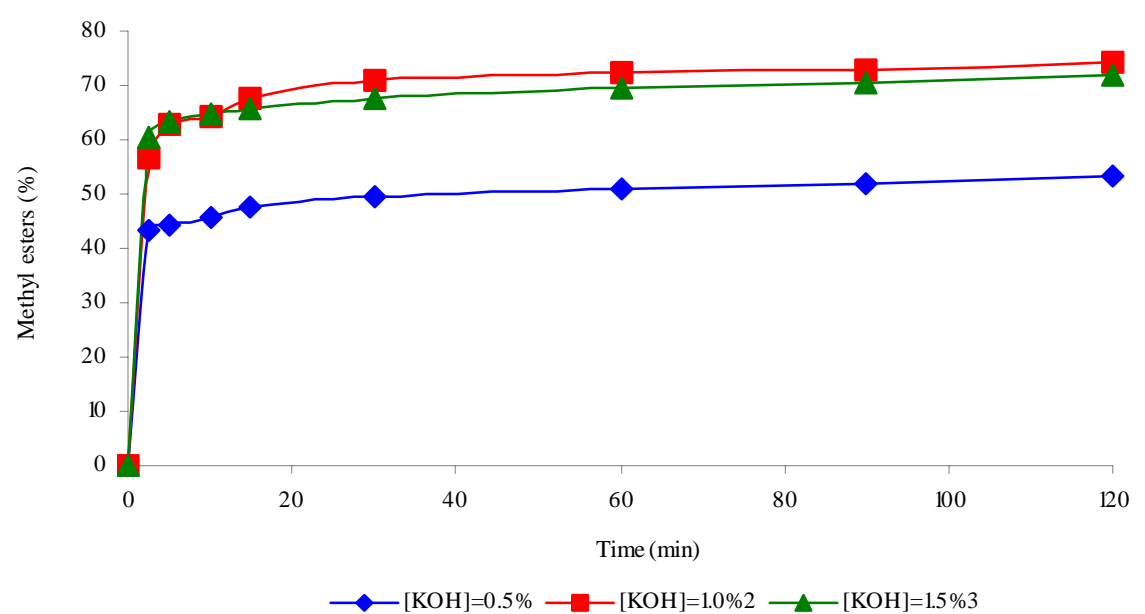

Fig. 6 Esters yield vs. time. Influence of catalyst concentration (Encinar et al., 2007) 
which increases the viscosity and leads to the formation of gels. These hinder the glycerol separation and, hence, reduce the apparent ester yield. The result of these two opposing effects is an optimal catalyst concentration that is about $1.0 \%$. Further increases in catalyst concentration will not increase the conversion (Fig. 6) and will lead to extra costs because it will be necessary to remove it from the reaction medium at the end (Encinar et al., 2005).

These results were confirmed by Chhetri et al. (2008) who carried out transesterification of WVO with $\mathrm{NaOH}$ concentrations at $0.2 \%$ increments starting from $0.4 \%$ to $1.2 \%$ and observed that the optimum conversion was achieved at $0.8 \% \mathrm{NaOH}$ concentration and that ester yield decreased with the increase in sodium hydroxide concentrations. Meng et al.(2008) also used $\mathrm{NaOH}$ as the catalyst in the transesterification of WCO and reported that $1 \mathrm{wt} \%$ (of oil) $\mathrm{NaOH}$ is the optimum catalyst concentration. Similarly, Yuan et al. (2008) carried out transesterification of waste rapeseed oil (using response surface methodology) and obtained maximum conversion at $1 \mathrm{wt} \%$ alkaline catalyst concentration.

\section{Reaction temperature}

Temperature has no detectable effect on the ultimate conversion to ester. However, higher temperatures decrease the time required to reach maximum conversion (Pinto et al., 2005). Transesterification can be conducted at various temperatures ranging from room temperature to the boiling point of the alcohol

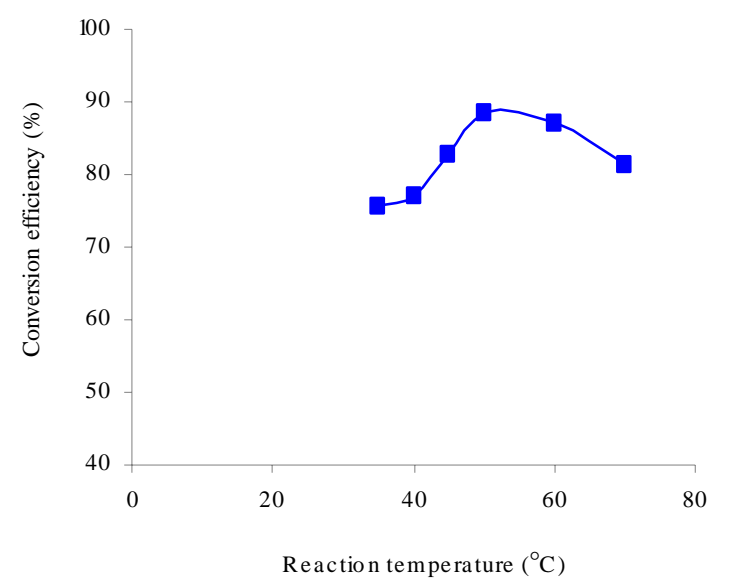

Fig. 7: Effect of temperature on the transesterification of WVO (Meng et al., 2008) employed $\left(68^{\circ} \mathrm{C}\right.$ in case of methanol) so that the reactor does not need to be pressurized (van Gerpen, 2005). Thus, the usual temperature used during transesterification in most literature is $60-65^{\circ} \mathrm{C}$. When the reaction temperature closes or exceeds the boiling point of methanol $\left(68^{\circ} \mathrm{C}\right)$, the methanol will vaporize and form a large number of bubbles which may inhibit the reaction (Meng et al., 2008).

Various researches have been carried out to find out the optimum temperature of the transesterification reaction. Refaat et al. (2008 a) reported an optimum temperature of $65^{\circ} \mathrm{C}$, while Meng et al. (2008) reported $50^{\circ} \mathrm{C}$ as the optimum temperature (Fig. 7). Yuan et al. (2008) carried out transesterification of waste rapeseed oil using response surface methodology and observed that maximum conversion occurred at $48.2^{\circ} \mathrm{C}$.

\section{Reaction time}

The completion of the basic-catalyzed transesterification process depends on reaction time. Most investigators have observed an optimum reaction time around $1 \mathrm{~h}$ (Tomasevic and Siler-Marinkovic, 2003; Meng et al., 2008; Refaat et al., 2008 a). It was reported that excess reaction time does not increase the conversion but favors the backward reaction (hydrolysis of esters) which results in a reduction of product yield (Leung and Guo, 2006). Felizardo et al. (2006) reported, however, that after $1 \mathrm{~h}$ of reaction, at methanol/oil molar ratio of 4.8 and using a catalyst concentration of $0.6 \%$ (by wt of oil) highest yield of ME was obtained which allowed an efficient separation of the ester phase. Yuan et al. (2008) carried out transesterification of waste rapeseed oil using response surface methodology and observed that maximum conversion occurred at $65.4 \mathrm{~min}$.

\section{Agitation}

Since this reaction can only occur in the interfacial region between the liquids and also due to the fact that fats and alcohols are not totally miscible, transesterification is a relatively slow process. As a result, vigorous mixing is required to increase the area of contact between the two immiscible phases (Singh and Fernando, 2006).

The agitation intensity appears to be of a particular importance for the alcoholysis process. The mass transfer of triglycerides from the oil phase towards the methanol-oil interface could be a critical step limiting the rate of alcoholysis reaction because the reaction mixture is heterogeneous, consisting of two immiscible 
phases. Poor mass transfer between two phases in the initial phase of the reaction results in a slow reaction rate, the reaction being mass transfer controlled (Noureddini and Zhu, 1997). Therefore, variations in mixing intensity are expected to alter the kinetics of the transesterification reaction. Stamenkovic et al., (2007) studied the effect of agitation intensity on alkalicatalyzed methanolysis of sunflower oil and reported that by using the microphotographic technique, drop size distributions were found to become narrower and shift to smaller sizes with increasing agitation speed as well as with the progress of the methanolysis reaction at a constant agitation speed.

It is evident, from the literature presented above, that methanol has been reported to give the best result in terms of biodiesel yield and byproduct recovery. The optimum reaction conditions for base-catalyzed transesterification using methanol (methanolysis) involve using the alcohol in excess of stoichiometric proportion (preferably 100\% excess) and using $\mathrm{KOH}$ or $\mathrm{NaOH}$ as a catalyst in a concentration of $1 \%$ of the weight of the oil. The temperature positively influences the biodiesel yield nearly up to about the boiling point of the alcohol (usually $60-65^{\circ} \mathrm{C}$ ) if other parameters are kept unchanged. Most investigators have observed an optimum reaction time around one hour; however, excess residence time can negatively influence the biodiesel production by favoring the backward reaction (hydrolysis of esters) which results in a reduction of product yield.

\section{Acid-catalyzed transesterification}

As previously stated, one limitation of base-catalyzed transesterification is its sensitivity to the purity of the reactants, especially to moisture and FFA content.

Freedman et al. (1986) have pointed out that acid catalysts are insensitive to FFA and are better than the alkaline catalysts for vegetable oils with FFA greater than $1 \%$. In fact, acid catalysts can simultaneously catalyze both esterification and transesterification. Thus, a great-advantage with acid catalysts is that they can directly produce biodiesel from low-cost lipid feedstock generally associated with high FFA concentrations, including waste frying oils (Lotero et al., 2005). Although the base-catalyzed process using virgin vegetable oil had the lowest fixed capital cost, the acid-catalyzed process using waste cooking oil was more economically feasible overall, providing a lower total manufacturing cost, a more attractive after-tax rate of return and a lower biodiesel break-even price (Zhang et al., 2003b).

Despite its insensitivity to free fatty acids in the feedstock, acid-catalyzed transesterification has been largely ignored mainly because of its relatively slower reaction rate (Zhang et al., 2003a). For acid catalyzed conversion of WVO with high FFA content, higher alcohol to oil ratio is required compared to basic catalyzed operation for better yield of biodiesel. Other disadvantages with this process are acidic effluent, no reusable catalyst and high cost of equipment (Wang et al., 2006)

Transesterification of triglycerides is usually catalyzed by inorganic acids such as sulfuric acid, hydrochloric acid, phosphoric acid and sulfonated organic acids. Freedman et al. (1984) investigated the transesterification of soybean oil with methanol using $1 \mathrm{wt} \%$ concentrated sulfuric acid (based on oil). They found that at $65^{\circ} \mathrm{C}$ and a molar ratio of 30:1 methanol to oil, it took $69 \mathrm{~h}$ to obtain more than $90 \%$ oil conversion to methyl esters. In addition, the authors established that the rate-limiting step varied over time and three regimes, in accordance with the observed reaction rate, could categorize the overall reaction process. Initially, the reaction was characterized by a mass-transfer controlled regime that resulted from the low miscibility of the catalyst and reagents; i.e., the nonpolar oil phase was separated from the polar alcohol-acid phase. As the reaction proceeded and ester products acted as emulsifiers, a second-rate regime emerged, which was kinetically controlled and characterized by a sudden surge in product formation. Finally, the last regime was reached once equilibrium was approached near reaction completion. Using higher molecular weight alcohols, such as butanol, brings about interesting advantages. For instance, butanol has better miscibility with the lipid feedstock than smaller alcohols, contributing to a less pronounced initial mass-transfer-controlled regime. Additionally, the elevated boiling points of larger alcohols enable the liquid reaction system to be operated at higher temperatures while maintaining moderate pressures. This is an important issue with the acid-catalyzed transesterification since higher reaction temperatures are often required to achieve faster reaction rates.

Al-Widyan and Al-Shyoukh (2002) studied the transesterification of waste palm oil under different conditions. Sulfuric acid and different concentrations of hydrochloric acid and ethanol at different excess 
levels were used. Using higher catalyst concentrations in the range of 1.5-2.25M produced biodiesel with lower specific gravity in a much shorter reaction time than lower concentrations. They have noticed that product specific gravity changes with reaction time in a roughly exponential fashion. Compared to $\mathrm{HCl}, \mathrm{H}_{2} \mathrm{SO}_{4}$ was a superior catalyst. Also, in the acid catalyzed transesterification of WVO, Zhang et al. (2003a) used a high molar ratio (100:1) of alcohol to oil. Higher excess level of alcohol consistently led to desirable lower values of specific gravity throughout the reaction time. In a more recent study, Zheng et al. (2006) studied the optimum process parameters and reaction kinetics in the acid catalyzed transesterification of waste frying oils, where they reported that the oil:methanol:acid molar ratios and the temperature were the most significant factors affecting the yield of FAME. At 70 ${ }^{\circ} \mathrm{C}$ with oil:methanol:acid molar ratios of 1:245:3.8, and at $80^{\circ} \mathrm{C}$ with oil:methanol:acid molar ratios in the range 1:74:1.9-1:245:3.8, the transesterification was essentially a pseudo-first-order reaction as a result of the large excess of methanol which drove the reaction to completion (99 $\pm 1 \%$ at $4 \mathrm{~h}$ ). They observed the conversion of waste frying oil to FAME as a function of methanol to oil molar ratio (at three different acid concentrations) as shown in Fig. 8. They also reported the effect of temperature on time course of conversion of waste frying oil to FAME during the course of the reaction and observed that in the presence of the large excess of methanol, free fatty acids present in the waste oil were very rapidly converted to methyl esters in the first few minutes under the above conditions. Little or

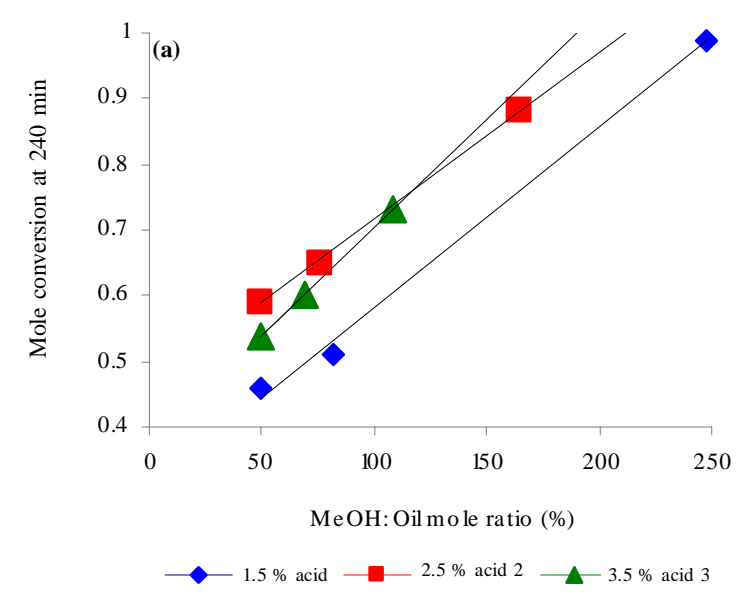

Fig. 8: Conversion of waste frying oil to FAME at $240 \mathrm{~min}$, as a function of methanol:oil molar ratios, at acid concentrations of 1.5, 2.5 or $3.5 \mathrm{~mol} \%$ at (a) $70{ }^{\circ} \mathrm{C}$; and (b) at $80{ }^{\circ} \mathrm{C}$; stirring speed, $400 \mathrm{rpm}$ (Zheng et al., 2006)

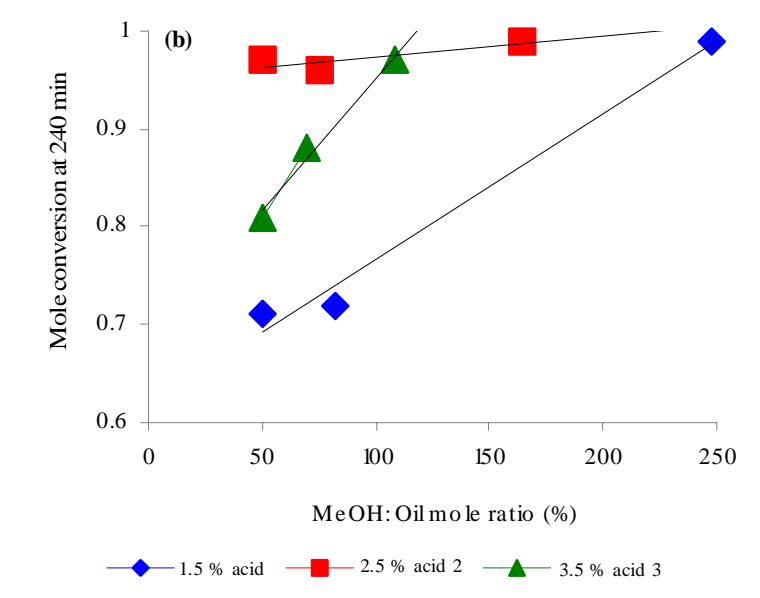

no monoglycerides were detected during the course of the reaction, and diglycerides present in the initial waste oil were rapidly converted to FAME.

It can be concluded that acid catalysts show better adaptability to FFAs than base catalysts and can catalyze esterification and transesterification simultaneously. However, it suffers some shortcomings such as high alcohol to oil molar ratio, high catalyst concentration and high temperature. Also, the reaction is relatively slow and the catalyst ends up in the byproducts causing serious separation problems. All these factors in addition to the serious environmental and corrosion-related problems limit their use.

\section{Two-step transesterification}

Both the base-catalyzed and the acid-catalyzed transesterification processes have their advantages and disadvantages as previously mentioned. Hence, to avoid the problems associated with the use of these catalysts separately, especially the problems of saponification in base-catalyzed and slow reaction time in acid-catalyzed transesterification, many researchers have adopted the two-stage transesterification. In the first stage, esterification of FFA present in waste frying oil is performed using acid to decrease the FFAs to a level less than $1 \%$. In the second stage, transesterification of the obtained oil is performed using an alkaline catalyst.

A comparison was held between the traditional acidcatalyzed transesterification using sulfuric acid as a catalyst and a two-step method using ferric sulfate (2.0 $\%$ ) catalyzed reaction followed by alkali (1.0\% potassium 
hydroxide) transesterification (Wang et al., 2006). The feedstock was waste cooking oil with the acid value of $75.92 \pm 0.04 \mathrm{mgKOH} / \mathrm{g}$. In both cases methanol was used and a reaction temperature of $95{ }^{\circ} \mathrm{C}$ was applied. The FAME yield in the two-step method was $97.22 \%$ at the reaction time of $4 \mathrm{~h}$, mole ratio of methanol to TG of 10:1, compared to $90 \%, 10 \mathrm{~h}$ and 20:1, respectively in the acid method. The authors argued that the two-step process showed advantages of no acidic wastewater, high efficiency, low equipment cost and easy recovery of catalyst compared with the limitations of acidic effluent, no reusable catalyst and high cost of equipment in the traditional acid process.

Hancsok et al. (2004), in an earlier study, used the combined acid/alkali-catalyzed transesterification (with cosolvent use) for the production of FAME from used frying oil with FFA $32.5 \%$, acid value $56 \mathrm{mg} \mathrm{KOH} / \mathrm{g}$ and iodine value $126 \mathrm{~g} \mathrm{I2/100} \mathrm{g.} \mathrm{Tetrahydrofuran} \mathrm{(THF)} \mathrm{and}$ dioxine were used as co-solvents while $\mathrm{H}_{2} \mathrm{SO}_{4}$ and sodium methylate were used as catalysts. In the first step a temperature of $60^{\circ} \mathrm{C}$, molar ratio of methanol and THF to oil 4:1, concentration of $\mathrm{H}_{2} \mathrm{SO}_{4} 15 \%$ and reaction time $0.5-6 \mathrm{~h}$. In the second step the temperature and molar ratio remained the same but $3 \%$ sodium methylate catalyst was used in a reaction time of $2 \mathrm{~h}$. The experiments were also repeated with dioxine under the same conditions. It was observed that the use of cosolvents significantly reduced the FFA content thereby reducing the reaction time during the first stage. With the combined transesterification, an ester yield greater than 96.5 \% was obtained. Fig. 9 shows the change in free fatty acid of the oil during the acidic pre-esterification in the absence of co-solvent (Fig. 9 a), in the presence of THF co-solvent (Fig. 9 b) and in the presence of dioxane co-solvent (Fig. 9 c). Issariyakul et al. (2006) studied the transesterification of waste fryer grease containing 5-6 \% (wt \%) FFA and showed that more than $90 \%$ ester was obtained when two-stage (acid and alkali catalyzed) method was used compared to $50 \%$ ester in single stage alkaline catalyst. Similar results were obtained by Encinar et al. (2007) who showed that the two-stage transesterification of waste frying oil was better than the one-stage process and the yields of the esters were improved $30 \%$ in relation with the one-stage transesterification. Cayli and Küsefoglu (2008) have, also, reported the results of comparing one-step and two-step base-catalyzed room temperature transesterification reaction of used cooking oil. In the two-step base catalyzed process, for each $1000 \mathrm{~g}$ of used cooking oil, $4.2 \mathrm{~g} \mathrm{NaOH}$ and $140 \mathrm{ml}$ methanol were used in the first step and $1.8 \mathrm{~g} \mathrm{NaOH}$ and $60 \mathrm{~mL}$ methanol were used in the second step. All reactions were done at $25{ }^{\circ} \mathrm{C}$; the effects of water content and suspended particles on the yield were studied. The yields were easily determined by Thermo Gravimetric Analysis (TGA) instead of the usual Gas chromatography (GC) and the viscosity of products was measured by a viscometer. It was found that the two-step process gives a better yield (96\%) than the one step process (86\%). A more recent study was conducted by Wan Omar et al. (2009) in an attempt to optimize the pre-treatment step of a two-step biodiesel production from waste cooking oil. Pretreatment with ferric sulphate in acid-catalyzed esterification process preceded transesterification in order to reduce the FFA level in the waste cooking oil. The authors investigated the relationship between reaction temperature, reaction time and methanol to oil molar ratio in the pre-treatment step. Central Composite Design (CCD) and Response Surface Methodology (RSM) were utilized to determine the best operating conditions for the pre-treatment step which were found to be $60{ }^{\circ} \mathrm{C}, 3 \mathrm{~h}$ and $7: 1$ for the reaction temperature, reaction time and methanol to oil molar ratio respectively, with (FAME) yield of $81.3 \%$.

Despite its advantages, the two-stage method also faces the problem of catalyst removal in both stages. The problem of catalyst removal in the first stage can be avoided by neutralizing the acid catalyst, using extra alkaline catalyst in the second stage. However, the use of extra catalyst will increase the cost of biodiesel.

\section{Transesterification using heterogeneous catalysts}

Heterogeneous (solid) catalysts have the general advantage of easy separation from the reaction medium and reusability. Heterogeneous catalysis is thus considered to be a green process. The process requires neither catalyst recovery nor aqueous treatment steps: the purification steps of products are then much more simplified and very high yields of methyl esters, close to the theoretical value, are obtained. Glycerin is directly produced with high purity levels (at least 98\%) and is exempt from any salt contaminants (Bournay et al., 2005). They are in general much more tolerant to water and FFAs in the feedstock. Furthermore, the use of heterogeneous catalysts does not lead to soap formation, and solid acid catalysts have the capacity to replace strong liquid acids, eliminating corrosion problems and the environmental threat posed by them 

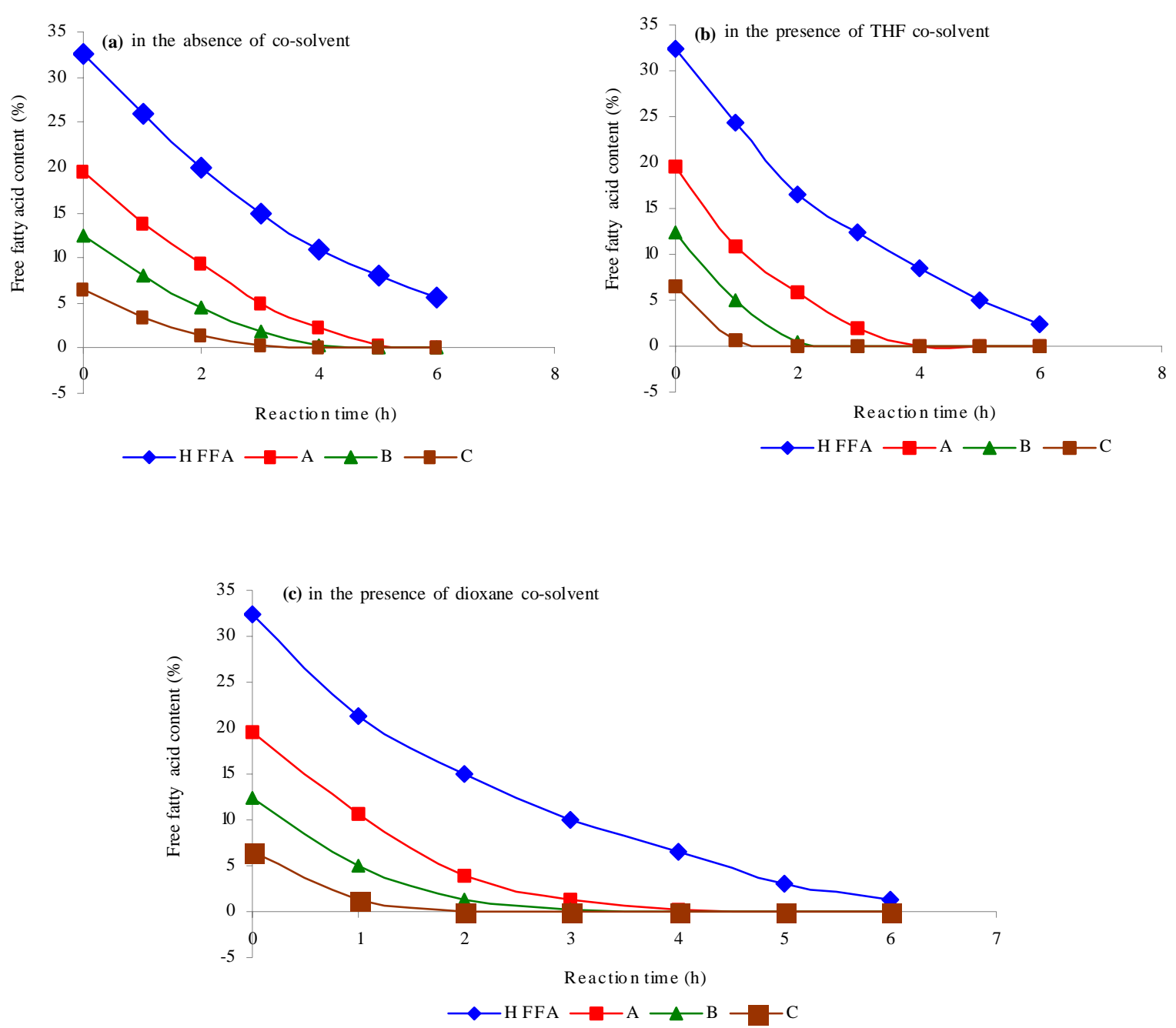

(H FFA=32.5\% initial free fatty acid content, $A=19.1 \%$ initial free fatty acid content, $\mathrm{B}=12.7 \%$ initial free fatty acid content, $\mathrm{C}=6.5 \%$ initial free fatty acid content)

Fig. 9: Change in free fatty acid of the oil during the acidic pre-esterification (Hancsok et al., 2004)

thus improving the sustainability of the biodiesel production process (Cao et al., 2008). However, heterogeneously catalyzed transesterification generally requires more severe operating conditions (relatively elevated temperatures and pressures) and the performance of heterogeneous catalysts is generally lower than that of the commonly used homogeneous catalysts. Moreover, one of the main problems with heterogeneous catalysts is their deactivation with time owing to many possible phenomena, such as poisoning, coking, sintering and leaching (Sivasamy et al., 2009). The problem of poisoning is particularly evident when the process involves used oils. More general and dramatic is catalyst leaching, which not only can increase the operational cost as a result of replacing the catalyst but also leads to product contamination. While purification of the reaction substrates, optimization of process parameters and inclusion of catalyst-regeneration steps can minimize the deactivation of heterogeneous catalysts, leaching phenomena can be minimized only by altering the catalyst formulation (Sivasamy et al., 2009).

In general, the use of solid catalysts to produce biodiesel requires a better understanding of the factors that govern their reactivity. To improve the performance of these catalysts, it is essential to understand the 
correlations between acid and base strength and catalytic activity. It is clear that the surface of these heterogeneous materials should display some hydrophobic character to promote the preferential adsorption of triglycerides and to avoid deactivation of catalytic sites by strong adsorption of polar by-products such as glycerol and water. Furthermore, it is important to enhance the interaction between the active phase and the support. This enhancement can be obtained by tuning the synthesis parameters, for instance, by designing embedded catalysts (Sivasamy et al., 2009). Thus far, it seems that an ideal solid acid catalyst should show some underlying characteristics, such as an interconnected system of large pores, a moderate to high concentration of strong acid sites and a hydrophobic surface (Lotero et al., 2005). Even though the best catalysts must have several qualities i.e., catalyze transesterification and esterification, not be deactivated by water, be stable, do not give rise to leaching, be active at low temperature, and have high selectivity (Di Serio et al., 2008). Heterogeneous catalysis for biodiesel production has been extensively investigated in the last few years. A great variety of materials have been tested as heterogeneous catalysts for the transesterification of vegetable oils; a broad classification of these materials is to categorize them as base or acid heterogeneous catalysts. Compared with solid base catalysts, solid acid catalysts have lower catalytic activity but higher stability, thus, they can be used for feedstock with large amount of FFAs without catalyst deactivation (Lotero et al., 2005).

\section{Acid zeolites}

Zeolites can be synthesized with extensive control of acidic/basic and textural properties. The acidic properties of zeolites are usually improved by protonation, that is, by exchange of the cations contained in the positively charged alumino-silicate cage with protons. Furthermore, it is possible to induce some hydrophobicity of zeolites by the elimination of water of hydration (Sivasamy et al., 2009). Koh and Chung (2008) have studied the transesterification of waste frying oil using various zeolite catalysts with different acidities and pore structures. Protonexchanged MOR, MFI, FAU and BEA zeolites were employed in the reaction with silicalite which has no strong acid sites. The authors found that the yield increased linearly with enhancing the acid strength and with increasing the amount of strong acid sites. Hence, proton-exchanged MOR(10) zeolite, which has more acid sites and greater acid strength than other zeolites, exhibited the highest yield of methyl esters (95\%). The authors also reported that dealumination to the HMOR zeolite induced decreasing of acid amount and acid strength, with consequent deactivation of the catalyst. They argued that the yields were independent on pore structure of the zeolites.

\section{Heteropolyacids}

Heteropolyacids (HPAs) are found to be active solid acid catalysts for their inherent advantages; such as strong Brønsted acidity better than $\mathrm{H}_{2} \mathrm{SO}_{4}$, easier separation and reusability, higher proton mobility and higher selectivity. Chai et al. (2007) investigated the use of heteropolyacid $\mathrm{Cs}_{2.5} \mathrm{H}_{0.5} \mathrm{PW}_{12} \mathrm{O}_{40}$ as a heterogeneous catalyst for the production of biodiesel. The results illustrated that the $\mathrm{Cs}_{2.5} \mathrm{H}_{0.5} \mathrm{PW}_{12} \mathrm{O}_{40}$ is an excellent environmentally benign solid acid catalyst for the production of biodiesel. It shows almost the same activity under the optimized reaction conditions as compared to a conventional homogeneous catalyst such as sodium hydroxide or sulfuric acid and can easily be separated from the products and can be used for several more runs. The most important features of this catalyst are that the catalytic activity is not affected by the content of free fatty acids and content of water in the vegetable oil and that the esterification can occur at a lower temperature (room temperature) and be finished within a shorter time. However, the relative water tolerance of the catalyst was limited to water content up to $1 \%$, over which the catalyst lost its catalytic activity. As continuation of this work, Cao et al. (2008) investigated the transesterification of waste cooking oil with high acid value and high water contents, using heteropolyacid $\mathrm{H}_{3} \mathrm{PW}_{12} \mathrm{O}_{40} \cdot 6 \mathrm{H}_{2} \mathrm{O}\left(\mathrm{PW}_{12}\right)$ as catalyst. The hexahydrate form of $\mathrm{PW}_{12}$ was found by the authors to be the most promising catalyst which exhibited highest ester yield $87 \%$ for transesterification of waste cooking oil and ester yield $97 \%$ for esterification of long-chain palmitic acid, respectively. The $\mathrm{PW}_{12}$ acid catalyst also showed higher activity under the optimized reaction conditions compared with conventional homogeneous catalyst sulfuric acid and can easily be separated from the products by distillation of the excess methanol and can be reused more times. The most important feature of this catalyst that the authors reported is that the catalytic activity 
is not affected by the content of free fatty acids and the content of water in the waste cooking oil and the transesterification can occur at a lower temperature $\left(65^{\circ} \mathrm{C}\right)$, a lower methanol oil ratio (70:1) and be finished within a shorter time $(14 \mathrm{~h})$. The results illustrated that $\mathrm{PW}_{12}$ acid is an excellent water-tolerant and environmentally benign acid catalyst for production of biodiesel from waste cooking oil. The most important parameters affecting the process are depicted in Fig. 10.

A more recent study by Li et al. (2009) showed that the use of a $\mathrm{ZnPW}$ nanotube catalyst containing

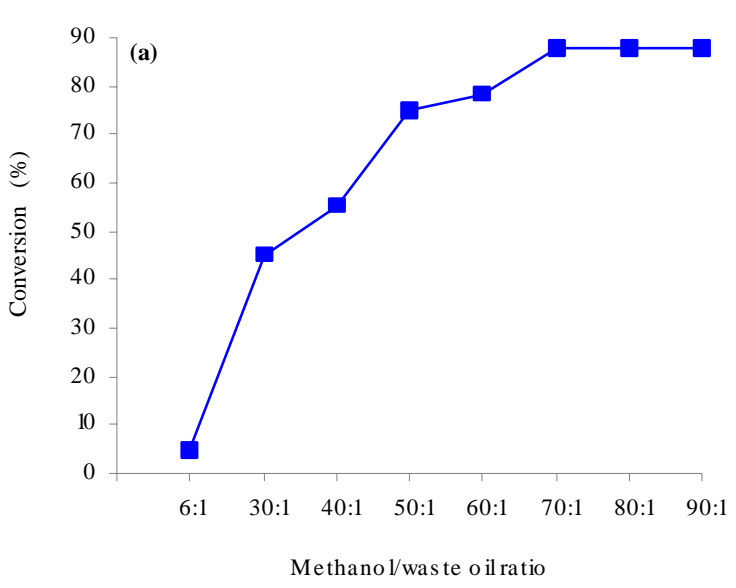

Influence of molar ratio of methanol to waste frying oil

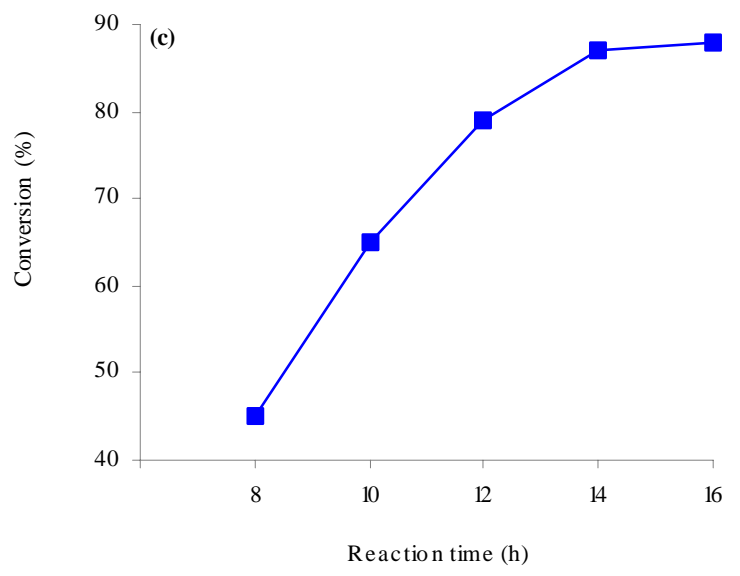

Effect of reaction time on the transesterification of waste frying oil
Bronsted and Lewis double acid sites promotes the conversion of waste cooking oil into biodiesel. The catalytic activity of the $\mathrm{ZnPW}$ nanotubes was stable to the presence of free fatty acids or water in the feedstock. The high catalytic activity of the ZnPW nanotubes is attributed to the synergistic effect of Lewis acid sites and Bronsted acid sites. Zinc dodecatungstophosphate $\left(\mathrm{Zn}_{1.2} \mathrm{H}_{0.6} \mathrm{PW}_{12} \mathrm{O}_{40}\right.$; ZnPW) nanotubes, which feature Lewis acid and Bronsted acid sites, were prepared using cellulose fibers as templates. The structure, acid properties, and catalytic activity of the nanotubes as heterogeneous catalysts for biodiesel

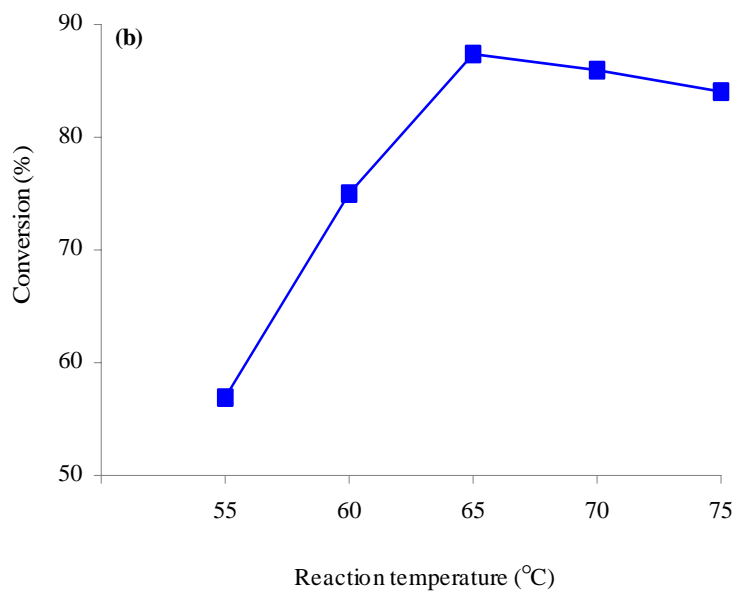

Influence of temperature on the transesterification of waste oil

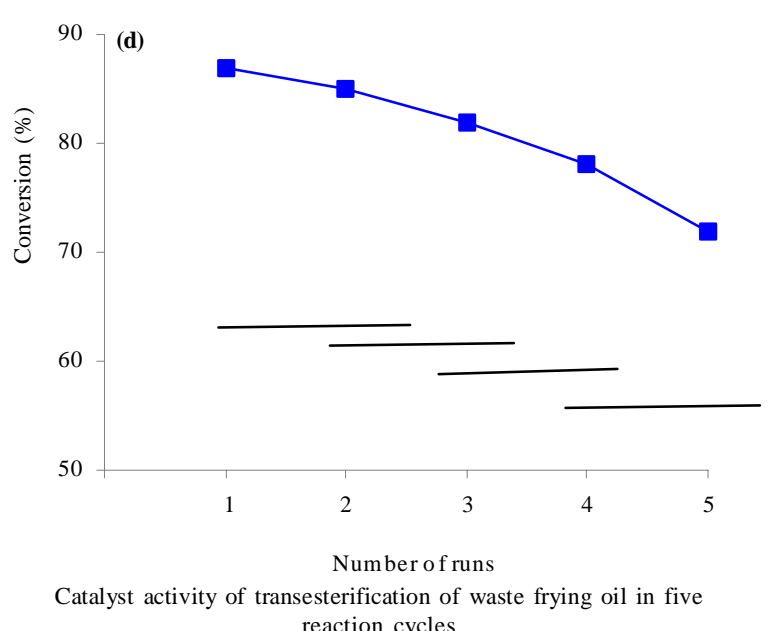

Fig. 10: Variables affecting the transesterification of waste frying oil by heteropolyacids: molar ratio of methanol/oil=70:1, time $=14 \mathrm{~h}$, temperature $=65^{\circ} \mathrm{C}, \mathrm{PW}_{12}$ catalyst $0.1 \mathrm{mmol}$ (Cao et al., 2008) 
production were then studied in detail. The ZnPW nanocatalyst exhibited higher catalytic activities for the simultaneous esterification and transesterification of palmitic acid than the parent acid catalyst 12tungstophosphoric acid $\left(\mathrm{H}_{3} \mathrm{PW}_{12} \mathrm{O}_{40}\right)$. Moreover, the doubly acidic nanotubes led to markedly enhanced yields of methyl esters in the conversion of waste cooking oil (containing 26.89 wt \% free fatty acids and $1 \%$ moisture) to biodiesel. The catalyst could be recycled and reused with negligible loss in activity over five cycles. The authors concluded that $\mathrm{ZnPW}$ nanocatalyst is acid- and water-tolerant and is an environmentally benign heterogeneous catalyst for the production of biodiesel from waste cooking oil.

Ion-exchange resins and immobilized sulfonic acids

Heterogeneous solid catalysts for the effective production of biodiesel from waste oils can be prepared by the incomplete carbonization of carbohydrates, such as D-glucose, sucrose, cellulose, and starch, followed by sulfonation. Zong et al. (2007) have prepared a sugar catalyst from D-glucose and have investigated its catalytic properties for the production of biodiesel from waste oils. Their results indicated that sugar catalysts are highly effective, minimally polluting and re-usable catalysts that are highly suited to the production of biodiesel from waste oils with a high acid value (Zong et al., 2007). In a preceding study by the same authors, carbohydrate-derived catalysts have been prepared from various carbohydrates such as D-glucose, sucrose, cellulose and starch. They found that the starch-derived catalyst had the best catalytic performance (Lou et al., 2008). The carbohydratederived catalysts exhibited substantially higher catalytic activities for both esterification and transesterification compared to the two typical solid acid catalysts (sulphated zirconia and Niobic acid) and gave markedly enhanced yield of methyl esters in converting waste cooking oils containing 27.8 wt \% high free fatty acids (FFAs) to biodiesel. In addition, under the optimized reaction conditions, the starchderived catalyst retained a remarkably high proportion (about $93 \%$ ) of its original catalytic activity even after 50 cycles of successive re-use and thus displayed very excellent operational stability. The authors argued that the results obtained clearly indicate that the carbohydrate-derived catalysts, especially the starchderived catalyst, are highly effective, recyclable, ecofriendly and promising solid acid catalysts that are highly suited to the production of biodiesel from waste oils containing high FFAs.

\section{Sulfated zirconia and mixed metal oxides}

Sulfated zirconia $\left(\mathrm{SO}_{4}^{2 "} / \mathrm{ZrO}_{2}\right)$, sulfated tin oxide $\left(\mathrm{SO}_{4}^{2 "} / \mathrm{SnO}_{2}\right)$ and sulfated titanium oxide $\left(\mathrm{SO}_{4}^{2 "} / \mathrm{TiO}_{2}\right)$ have been studied to catalyze the transesterification of vegetable oils owing to their superacidity. These catalysts have showed good catalytic activities (Furuta et al., 2004; Jitputti et al., 2006; Kiss et al., 2006) and good stability when used to catalyze esterification and transesterification simultaneously. However, they have not been generally used in the industrial production process, mainly because of the high catalyst cost and difficulty in filtering the small catalyst particles. The activities of three modified-zirconias (titania zirconia, sulfated zirconia and tungstated zirconia) were evaluated for both esterification and transesterification reactions (Lopez et al., 2008). The study provided a quantitative comparison of the rate of transesterification and conversion of TGs versus the rate of esterification of FFAs under simultaneous reaction conditions, which is of great importance when using less pure biodiesel feedstocks (as waste cooking oil). As expected, esterification occurred at a much faster rate than transesterification. However, under simultaneous reaction conditions, by virtue of the water being produced in esterification and hydrolysis of the TG taking place, the conversion of the triglycerides to ester products was greatly increased. Although the fresh sulfated zirconia (SZ) catalyst was found to be the most active for these reactions, its activity was not easily regenerated. Titania zirconia (TiZ) was found to have a greater activity for transesterification than tungstated zirconia (WZ). However, the opposite result was found for esterification. The higher activity of TiZ towards transesterification is suggested to be due to its base sites, which are likely poisoned in the presence of the carboxylic acid during esterification. WZ was found to be the most suitable of these catalysts for carrying out these reactions as it is more active than TiZ for esterification and can be more easily regenerated than SZ by simple re-calcination in air.

Peng et al. (2008) studied the activity of a solid acid catalyst comprising $\mathrm{SO}_{4}^{2-} / \mathrm{TiO}_{2}-\mathrm{SiO}_{2}$ for the production of biodiesel from several low cost feedstocks with high FFAs. The optimized reaction parameters were reaction temperature $200{ }^{\circ} \mathrm{C}$, molar ratio of methanol to oil 9:1 
and catalyst concentration $3 \mathrm{wt} \%$. They reported that the catalyst showed good stability, can be recycled, easily removed and can simultaneously catalyze esterification and transesterification. A continuous process for biodiesel production from cheap raw feedstocks was proposed and a 10,000-tons/y biodiesel production demonstration plant has been built.

Various solid acid catalysts were evaluated by Jacobson et al. (2008) for the production of biodiesel from low quality oil such as (WCO) containing $15 \mathrm{wt} \%$ free fatty acids. The authors found that zinc stearate immobilized on silica gel (ZS/Si) was the most effective catalyst in simultaneously catalyzing the transesterification of triglycerides and esterification of free fatty acid (FFA) present in WCO to methyl esters. They reported that by optimization of reaction parameters with the most active ZS/Si catalyst at 200 ${ }^{\circ} \mathrm{C}, 1: 18$ oil to alcohol molar ratio and $3 \mathrm{wt} \%$ catalysts loading, a maximum ester yield of 98 wt \% could be obtained. The catalysts were recycled and reused many times without any loss in activity. The results showed that the fresh and used ZS/Si catalysts had a similar $\mathrm{Zn}$ content of about $6.0 \%$. The presence of large pores and the existence of active ZS species (even after reaction for four times) contribute to the overall activity and stability of ZS/Si catalyst. Further, studies are in progress to investigate the correlation between catalytic activity and concentration, type of acid sites in the catalyst.

Hence, it can be concluded that the use of solid acid catalysts can offer many advantages as: they are insensitive to FFA content, they can perform esterification and transesterification simultaneously, they can be easily separated from the products, they show good stability and can be recycled and they are environmentally friendly. However, the process deserves to be further investigated. Positive results should be expected if more research efforts are directed to this field.

\section{Enzymatic transesterification}

There is a current interest in using enzymatic catalysis to commercially convert vegetable oils and fats to FAME as biodiesel fuel, since it is more efficient, highly selective, involves less energy consumption (reactions can be carried out in mild conditions) and produces less side products or waste (environmentally favorable) (Akoh et al., 2007). However, the drawbacks of enzymatic catalysts are significantly higher production cost (Meher et al., 2006) as well as difficulty during manufacturing due to the need for a careful control of reaction parameters (Cerveró et al., 2008).

The enzymatic conversion is based on the use of biocatalysts as lipases that, on one hand, catalyze the hydrolysis of fats and vegetable oils with release of glycerol and, on the other hand, in the presence of short chain alcohols, favor the formation of linear chain esters. Enzymes have several advantages over chemical catalysts such as mild reaction conditions; specificity, reuse; and enzymes or whole cells can be immobilized, can be genetically engineered to improve their efficiency, accept new substrates, are more thermostable and are considered natural, and the reactions they catalyze are considered "green" reactions (Akoh et al., 2007). The reuse of lipases and the recovery of their stability, both thermal and mechanical, are the most significant issues for making the enzymatic process, whose costs are still too high, more competitive for biodiesel production. A major problem with lipase reaction with methanol is enzyme inactivation by methanol. The stepwise addition of methanol can prevent the inactivation of the lipase and allow its continued usability (Watanabe et al., 2001). Immobilized lipases permit to achieve this goal (Shimada et al., 2002). However, they can be maximally exploited only if operating conditions are optimized; a task which requires knowledge of reaction kinetics and, in general, predictions of process performance (De Paola et al., 2009)

Engineering of enzymatic biodiesel synthesis processes requires optimization of such factors as: molar ratio of substrates (alcohol:triacylglycerols), temperature, type of organic solvent (if any) and water activity. All of them are correlated with properties of lipase preparation (Antczak et al., 2009). In addition, knowledge about water content, free fatty acid level, percent conversion, acyl migration and substrate flow rate in packed bed bioreactors) are required to improve the yield of biodiesel (Akoh et al., 2007). For the use of enzymes, there are some critical factors: There is a minimum water content needed by the lipase, below which it does not work; alcohol has an effect on the reaction, being methanol the most commonly employed; the effect of temperature effect is significant because instead of increasing the reaction rate by increasing temperature, enzymes can become denatured at high temperatures; and obviously the raw material is important, because not all oils have the same amount 
or type of fatty acids and lipase specificity can become more attractive in some oils than in others (Cerveró et al., 2008).

Chen et al. (2006) have investigated the enzymatic conversion of waste cooking oils into biodiesel. Enzymatic conversion using immobilized lipase based on Rhizopus orzyae was considered and the technological process was studied focusing on optimization of several process parameters, including the molar ratio of methanol to waste oils, biocatalyst load and adding method, reaction temperature and water content. The results indicated that methanol/oils ratio of $4: 1$, immobilized lipase/oils of $30 \mathrm{wt} \%$ and $40^{\circ} \mathrm{C}$ are suitable for waste oils under $1 \mathrm{~atm}$. The irreversible inactivation of the lipase is presumed and a stepwise addition of methanol to reduce inactivation of immobilized lipases was proposed. Under the optimum conditions the yield of methyl esters was around 88$90 \%$.

A more recent study by Maceiras et al. (2009) was also conducted to investigate the enzymatic conversion of waste cooking oils into biodiesel using immobilized lipase Novozym 435 as catalyst. The effects of methanol to oil molar ratio, dosage of enzyme and reaction time were investigated. The optimum reaction conditions for fresh enzyme were methanol to oil molar ratio of $25: 1,10 \%$ of Novozym 435 based on oil weight and reaction period of $4 \mathrm{~h}$ at $50^{\circ} \mathrm{C}$ obtaining a biodiesel yield of $89.1 \%$. Moreover, the reusability of the lipase over repeated cycles was also investigated under standard conditions. Best results were obtained with the reused enzyme and low oil molar ratio (1:1). From these results the authors concluded that: (i) Novozym 435 is not deactivated by methanol in the operating conditions used, (ii) external mass transfer can be the limiting step in the oil transesterification working with high concentration on immobilized enzyme and (iii) the excess of methanol interferes with the separation of methyl ester causing an apparent lost of product by increasing solubility of glycerol (Fig. 11).

Li et al. (2009) presented an inexpensive self-made immobilized lipase from Penicillium expansum which was shown to be an efficient biocatalyst for biodiesel production from waste oil with high acid value in organic solvent. It was revealed that water from the esterification of free fatty acids and methanol prohibited a high methyl ester yield. The authors showed that adsorbents could effectively control the concentration of water in the reaction system, resulting in an improved methyl ester yield. Silica gel was proved to be the optimal adsorbent, affording a ME yield of $92.8 \%$ after $7 \mathrm{~h}$. Moreover, the enzyme preparation displayed a higher stability in waste oil than in corn oil, with $68.4 \%$ of the original enzymatic activity retained after being reused for 10 batches (Fig. 12).

Reaction kinetics can be studied through a fundamental approach based on kinetics modeling, but other factors than kinetics can also affect the reaction progress. An accurate study of the effects and interactions of process operating conditions, such as mixing and reactor fluid-dynamics, on the system performance is necessary to set the bases of bioreactors design. Fluid-dynamics is a relevant aspect in the bioreactor design also because of its influence on mass transport phenomena. However, the effect of mixing on process performance is hardly predictable by means of fundamental modelling; in this regard factor analysis becomes an efficient tool to evaluate the effect of such parameter. It is based on experimental design and optimization with the aim of understanding the effect of each significant parameter on the process performance, defined as substrates final conversion or final products concentration. De Paola et al. (2009) have implemented a factor analysis in order to evaluate the effect of operating parameters on yields of biodiesel production from waste oil. The two variables considered are mixing rate and enzyme loading, since it has been recognized that they affect process performance singularly and through interaction effects. These variables were subjected to a factor analysis and their combined effect on the reaction performance was determined. Response surface methodology (RSM) was used based on a linear first order model (steepest ascent method) and on a second order one in proximity of the optimal solution. The authors have established a model able to predict reaction performance within the range of mixing rates and enzyme amount considered for model formulation and outside of it and showed that best performances were obtained at high stirring and high enzyme loading.

Using the tools of recombinant DNA technology, it is possible to increase the supply of suitable lipases for biodiesel production. Protein engineering and sitedirected mutagenesis may be used to alter the enzymesubstrate specificity, stereospecificity and thermostability, or to increase their catalytic efficiency, which will benefit biodiesel production and lower the cost of the overall process (Akoh et al., 2007). 
The enzymatic approach is environmentally friendly, considered a "green reaction", however, the cost of the final enzymatic product remains a hurdle compared to the cheaper alternative of using chemical catalysis. The process needs to be explored for industrial production of biodiesel and more work has to be done to justify its industrial application in the future.

\section{Non-catalytic transesterification}

The non-catalyst options were designed to overcome the reaction initiation lag time caused by poor methanol and oil miscibility. An improved process was investigated for methanolysis of vegetable oil. The process comprises solubilizing oil in methanol by addition of a cosolvent in order to form a one-phase reaction mixture, Tetrahydrofuran (THF) is chosen as a cosolvent because its boiling point is close to that of methanol, so that at the end of the reaction the unreacted methanol and THF can be co-distilled and recycled. At the 6:1 methanol-oil molar ratio, the addition of 1.25 volume of tetrahydrofuran per volume of methanol produces an oil dominant one phase system in which methanolysis speeds up dramatically to 5-10 min, at ambient temperatures, atmospheric pressure and without agitation. No catalyst residues in either the ester or the glycerol phase (Meher et al,
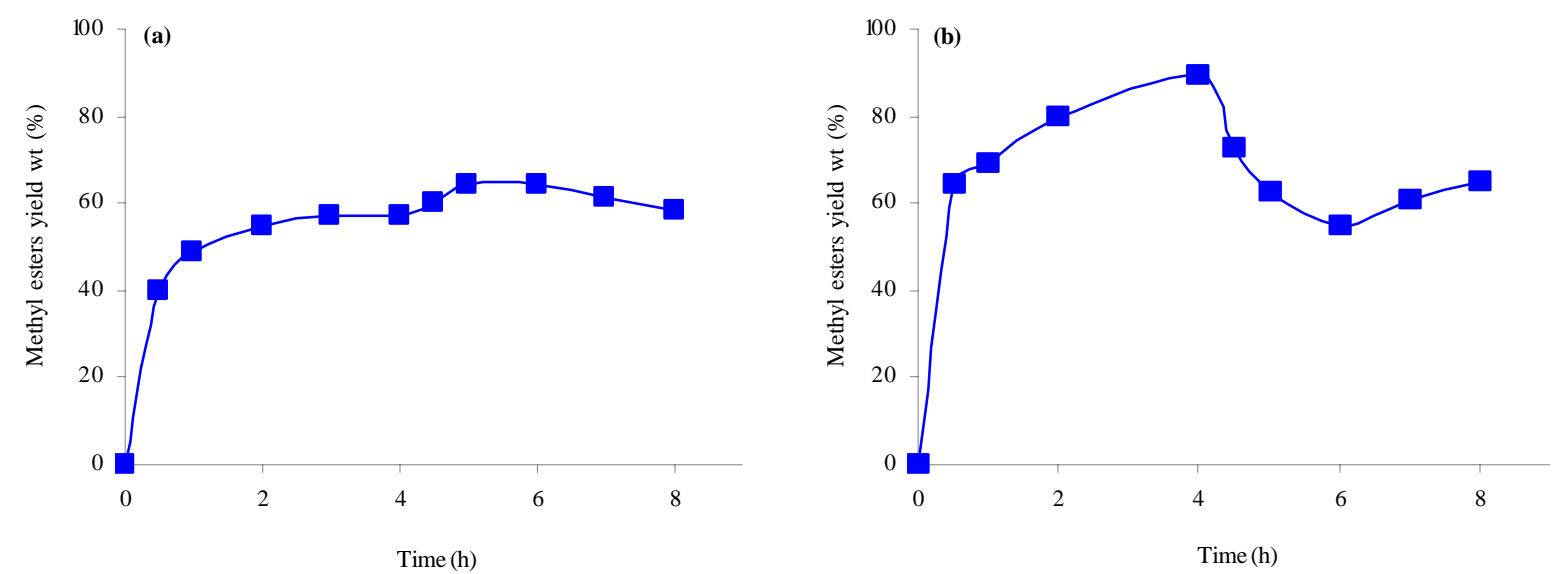

Fig. 11: Effect of enzyme addition on methanolysis WFO at different alcohol-oil molar ratio: (a) 1:1, (b) 25:1. Reaction conditions: first-step: WFO $2 \mathrm{~g}$; $10 \mathrm{wt} \%$ immobilized C. antarctica; reaction temperature $50{ }^{\circ} \mathrm{C}$; reaction time $4 \mathrm{~h}$. Second step was conducted under the same conditions after $10 \%$ of fresh enzyme was added in the reaction mixture (Maceiras et al., 2009)

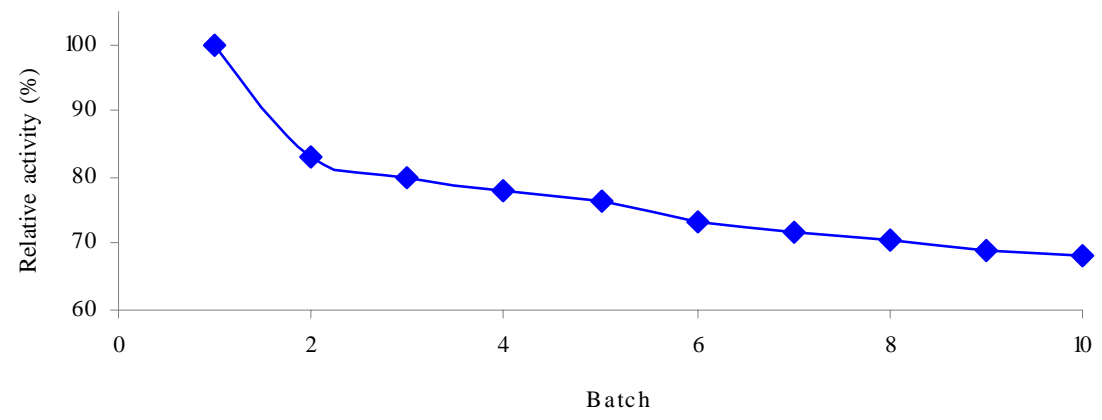

Fig. 12: Operational stability of immobilized PEL. The reaction was performed at $35{ }^{\circ} \mathrm{C}$ and $200 \mathrm{rpm}$ by adding one molar equivalent of methanol into the mixture containing $2 \mathrm{~g}$ waste oil, $0.4 \mathrm{~g} \mathrm{t}$-amyl alcohol, $0.96 \mathrm{~g}$ blue silica gel and $168 \mathrm{U}$ immobilized PEL. Each one molar equivalent of methanol was added at 1 and $3 \mathrm{~h}$, respectively. The three steps served as one batch with total reaction time being $7 \mathrm{~h}$ (Li et al., 2009) 
2006). The co-solvent increases the rate of reaction by making the oil soluble in methanol, thus increasing contact of the reactants.

Another non-catalytic approach is the use of methanol at very high temperature and pressure. This is known as supercritical methanol. Under supercritical conditions (350-400 ${ }^{\circ} \mathrm{C}$ and $\left.>80 \mathrm{~atm}\right)$ and at high (42:1) alcohol to oil ratio, the reaction is complete in about 4 minutes (Kusdiana and Saka, 2001). In addition to the high conversion and reaction rates, supercritical transesterification is appealing as it can tolerate feedstock with very high contents of FFAs and water, up to 36 wt \% and 30 wt \%, respectively (Warabi et al., 2004). The supercritical method is a catalyst-free approach which simplifies the recovery of glycerin as a co-product for biodiesel production and could potentially be a solution to many processing problems. However, the reactor sizes would be larger compared to the normal method for biodiesel production due to the higher amount of alcohol used. Capital and operating costs are higher and energy consumption higher.

Many researchers have focused on how to decrease the severity of the reaction conditions. Co-solvents, such as carbon dioxide, hexane and calcium oxide, added into the reaction mixture can decrease the operating temperature, pressure and the amount of alcohol. Examples of the co-solvents used for this purpose are propane (Cao et al., 2005), calcium oxide (Demirbas, 2007) and carbon dioxide (Han et al., 2005; Yin et al., 2008). Han demonstrated that, with an optimal reaction temperature of $280^{\circ} \mathrm{C}$, methanol to oil ratio of 24 and $\mathrm{CO}_{2}$ to methanol ratio of 0.1 , a $98 \%$ yield of methyl esters (biodiesel) was observed in $10 \mathrm{~min}$ at a reaction pressure of $14.3 \mathrm{MPa}$, which makes the production of biodiesel using supercritical methanol viable as an industrial process (Han et al., 2005). Whereas Yin showed that with $\mathrm{CO}_{2}$ or hexane as cosolvent in the reaction system and at an optimal reaction temperature of $160 \mathrm{p} \mathrm{C}$ and methanol to oil ratio of 24, a $98 \%$ yield of methyl esters was observed in $20 \mathrm{~min}$. (Yin et al., 2008).

West et al. (2008) carried out assessment of four biodiesel production processes using HYSYS. The first two employed traditional homogeneous alkali and acid catalysts. The third and fourth processes used a heterogeneous acid catalyst and a supercritical method to convert a waste vegetable oil feedstock into biodiesel. The authors established that while all four processes were capable of producing biodiesel at high purity, the heterogeneous and supercritical processes were the least complex and had the smallest number of unit operations. Material and energy flows, as well as sized unit operation blocks, were used to conduct an economic assessment of each process. Total capital investment, total manufacturing cost and after tax rateof-return were calculated for each process. The heterogeneous acid catalyst process had the lowest total capital investment and manufacturing costs and had the only positive after tax rate-of-return. The high solvent (glycerol for washing) and catalyst costs of the alkali-catalyzed process, the large excesses of methanol in homogeneous acid-catalyzed and the supercritical processes resulted in much higher manufacturing costs than in the heterogeneous acid catalyst process. The transesterification reactor forms a large part of the capital cost, especially for the homogeneous acid-catalyzed and the supercritical processes in which the large reactor was required to contain a large material flow.

van Kasteren and Nisworo (2007) described a conceptual design of a production process in which waste cooking oil is converted via supercritical transesterification with methanol to methyl esters (biodiesel) at industrial scale and concluded that supercritical transesterification can be scaled up to yield high purity methyl esters (99.8\%) and almost pure glycerol with added advantages of elimination of pretreatment related capital and operating costs.

Wen et al. (2009) presented a review on supercritical fluid technology for biodiesel production indicating some prominent merits which the SCF technology possesses that includes fast kinetics, high fuel production rate, ease of continuous operation and elimination of the necessity of catalysts. They added that the harsh operation environment, i.e. the high temperature and high pressure and its request on the materials and associated cost are the main concerns for its wide application. Demirbas (2009) by comparing the effects of base-catalytic and supercritical methanol transesterification of waste cooking oil reached a similar conclusion and pointed out that the great advantages of supercritical methanol are: (a) no catalyst required; (b) not sensitive to both water and free fatty acid; (c) free fatty acids in the waste cooking oil are transesterified simultaneously (Fig. 13).

It can be concluded that the supercritical technology has been shown to be a promising technique for future large-scale biodiesel production especially from waste 
oil. However, the supercritical technology suffers from certain drawbacks including the harsh operation environment and high cost.

\section{Emerging technologies in transesterification} Biodiesel production using ultrasonication

As previously mentioned on discussing the effect of agitation on the base-catalyzed transesterification process, the mass transfer of triglycerides from the oil phase towards the methanol-oil interface could be a critical step limiting the rate of alcoholysis reaction because the reaction mixture is heterogeneous, consisting of two immiscible phases. As a result, a vigorous mixing is required to increase the area of contact between the two immiscible phases and thus to produce an emulsion. Low frequency ultrasonic irradiation is a useful tool for emulsification of immiscible liquids (Colucci et al., 2005). The collapse of the cavitation bubbles disrupts the phase boundary and causes emulsification by ultrasonic jets that impinge one liquid to another (Hanh et al., 2008). Hence, ultrasonication can provide the mechanical energy for mixing and the required energy for initiating the transesterification reaction. Like any sound wave, ultrasound alternately compresses and stretches the molecular spacing of the medium through which it passes, causing a series of compression and rarefaction cycles. If a large negative pressure gradient is applied to the liquid so that the distance between the molecules exceeds the critical molecular distance necessary to hold the liquid intact, the liquid will break down and voids (cavities) will be created, i.e., cavitation bubbles will form. At high ultrasonic intensities, a small cavity may grow rapidly through inertial effects. As a result, some bubbles undergo sudden expansion to an unstable size and collapse violently, generating energy for chemical and mechanical effects and may increase the mass transfer rates by disrupting the interfacial boundary layers (known as the liquid jet effect). Another effect of ultrasound agitation is acoustic streaming mixing, in which a macroscopic flow is induced in the liquid by the absorption of the ultrasonic wave by the reactive medium (Colucci et al., 2005).

Wu et al. (2007) reported that ultrasonic mixing produced smaller droplet sizes than conventional agitation, leading to more interfacial area for the reaction to occur. By studying the effect of ultrasonication on droplet size in biodiesel mixtures, the authors concluded that ultrasonication can result in mean droplet sizes much lower than those generated by conventional agitation, and can be a more powerful tool in breaking methanol into small droplets.

The ultrasound in the chemical processing enhances both the mass transfer and chemical reactions. It offers the potential for shorter reaction times, cheaper reagents and less extreme physical conditions, leading to less expensive and smaller chemical plants (Hanh et al., 2008). Many studies have investigated the effect

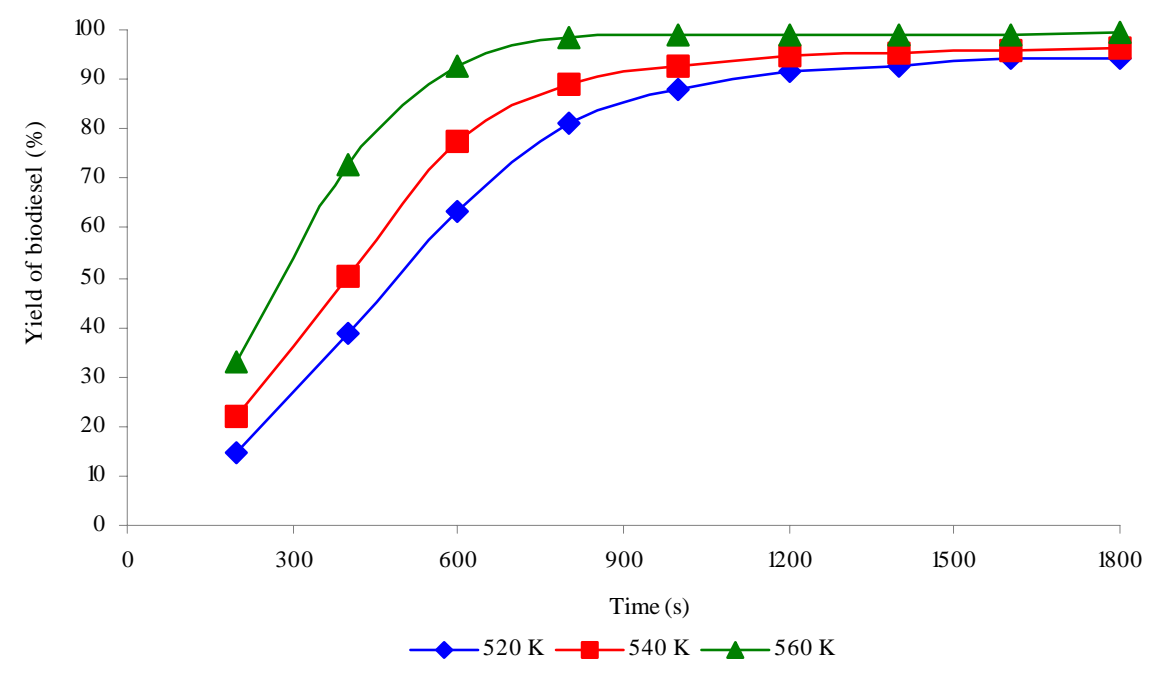

Fig. 13: Plots for yield of biodiesel form waste cooking oil vs time at different temperatures using supercritical methanol. Molar ratio of methanol to waste cooking oil: 41:1 (Demirbas, 2009) 
of ultrasonication on the transesterification process for producing biodiesel and reported the optimum reaction conditions (Stavarache et al., 2005; Singh and Fernando, 2006; Stavarache et al., 2007 a; Hanh et al., 2008; Kelkar et al., 2008). These previous studies reported excellent ester yields (98-99\%) with a low amount of catalyst in much shorter time than the mechanical stirring. Ultrasonic irradiation also proved suitable for large-scale continuous processing of vegetable oils since relatively simple devices can be used to perform the reaction (Stavarache et al., 2007b).

Refaat and El Sheltawy (2008) compared the use of ultrasonication for fast production of biodiesel from waste vegetable oil with the conventional basecatalyzed transesterification and concluded that transesterification by low frequency ultrasound (20 $\mathrm{kHz}$ ) offered a lot of advantages over the conventional classical procedure. It proved to be efficient (biodiesel yield up to 98-99\%), as well as time and energy saving (dramatic reduction of reaction time to $5 \mathrm{~min}$, compared to one hour or more using conventional batch reactor systems and remarkable reduction in static separation time to $25 \mathrm{~min}$, compared to $8 \mathrm{~h}$ ).

\section{Microwave-enhanced transesterification}

Thermally driven organic transformations can take place by conventional heating where the reactants are slowly activated by an external heat source. Heat is driven into the substance, passing first through the walls of the vessel in order to reach the solvent and reactants. This is a slow and inefficient method for transferring energy into the reacting system. Alternatively, microwave-accelerated heating can be employed where microwaves couple directly with the molecules of the entire reaction mixture, leading to a rapid rise in temperature. Since the process is not limited by the thermal conductivity of the vessel, the result is an instantaneous localized superheating of any substance that will respond to either dipole rotation or ionic conduction - the two fundamental mechanisms for transferring energy from microwaves to the substance(s) being heated (Hayes, 2004).

In the electromagnetic radiation spectrum, the microwave radiation region is located between infrared radiation and radio waves. Microwaves (MW) have wavelengths of $1 \mathrm{~mm}$ - $1 \mathrm{~m}$, corresponding to frequencies between 0.3 - $300 \mathrm{GHz}$. In general, in order to avoid interference, industrial and domestic microwave apparatus are regulated to $12.2 \mathrm{~cm}$, corresponding to a frequency of $2.45 \mathrm{GHz}$, but other frequency allocations do exist (Mingos and Baghurst, 1991; Fini and Breccia, 1999).

Microwaves, a non-ionizing radiation incapable of breaking bonds, are a form of energy and not heat and are manifested as heat through their interaction with the medium or materials wherein they can be reflected (metals), transmitted (good insulators that will not heat) or absorbed (decreasing the available microwave energy and rapidly heating the sample) (Varma, 2001). Microwaves, representing a non-ionizing radiation, influence molecular motions such as ion migration or dipole rotations, but not altering the molecular structure.

A molecule possessing a dipole moment is sensitive to external electric fields. Therefore,, when it is exposed to microwave irradiation, the dipole will attempt to align with the applied electric field by rotation. The applied field provides the energy for this rotation. In the microwave radiation region, the frequency of the applied irradiation $(2.45 \mathrm{GHz})$ is low enough so that the dipoles will have time to respond to the alternating electric field and therefore will rotate. However, the frequency is not high enough for the rotation to follow the oscillating field exactly generating a phase difference between the orientation of the field and that of the dipole. The continual reorientation of the molecules results in friction giving rise to dielectric heating (Lidstrom et al., 2001). If a molecule is charged, then the electric field component of the microwave irradiation will move the ions back and forth through the sample while also colliding them into each other. This movement again generates heat. The conductivity mechanism is a much stronger interaction than the dipolar mechanism with regard to the heat generating capacity (Lidstrom et al., 2001). In the transesterification process, because the mixture of vegetable oil, methanol and potassium hydroxide contains both polar and ionic components, rapid heating is observed upon microwave irradiation and because the energy interacts with the sample on a molecular level, very efficient heating can be obtained.

To allow for a strict comparison between microwave irradiation and conventional heating under similar conditions (reaction medium, temperature and pressure), a monomode microwave reactor should be used. This ensures wave focusing (reliable homogeneity in the electric field) and accurate control of the temperature (using an optical fibre or infrared 
detection) throughout the reaction (Perreux and Loupy, 2001). Reflux system has been developed in an effort to use solvents in microwave assisted organic synthesis without the risk of explosion. Reflux systems are at minimal risk of explosion because they are operating at atmospheric pressure and because flammable vapors cannot be released into the microwave cavity. Several examples of microwave irradiated transesterification methods have been reported using adapted domestic ovens to use them as flow systems (Saiffudin et al., 2004) or batch laboratory ovens (Mazzocchia et al., 2004) but only moderate conversions were obtained.. A more recent study used homogeneous catalysis, both in a batch and in a flow system (Hernando et al., 2007). Leadbeater and Stencel reported the use of microwave heating as a fast, simple way to prepare biodiesel in a batch mode (Leadbeater and Stencel, 2006). This was followed by a continuousflow approach allowing for the reaction to be run under atmospheric conditions and performed at flow rates of up to $7.2 \mathrm{~L} / \mathrm{min}$ using a $4 \mathrm{~L}$ reaction vessel. (Barnard et al., 2007). In a study by Refaat et al. (2008b) the optimum parametric conditions obtained from the conventional technique were applied using microwave irradiation in order to compare both systems for the production of biodiesel from neat and waste vegetable oils. The results showed that application of radio frequency microwave energy offers a fast, easy route to this valuable biofuel with advantages of enhancing the reaction rate and improving the separation process. From these results it was concluded that using microwave irradiation reduces the reaction time by $97 \%$ and the separation time by $94 \%$. The methodology allowed for the use of high free fatty acid content feedstock, including used cooking oil without prior pretreatment processes. The authors also proved that microwave-enhanced biodiesel is not, at least, inferior to that produced by the conventional technique.

A study was conducted by El Sheltawy and Refaat (2008) to compare three options for the production of biodiesel from neat and waste vegetable oil; the conventional base-catalyzed transesterification, ultrasonication and microwave-enhanced ansesterification. Despite the prominent advantages the ultrasonication and microwave technologies offer compared to the conventional base-catalyzed transesterification, yet, these emerging technologies need to be further investigated for possible scale-up for industrial application.

\section{Performance tests of wvo-based biodiesel}

Operationally, biodiesel performs very similar to low sulfur diesel in terms of power, torque and fuel consumption without major modification of engines or infrastructure (van Gerpen, 2005). Compared to petroleum diesel, the engine efficiency is not significantly affected by using biodiesel (Dorado et al., 2003a). However, an increase in fuel consumption is observed. This increase is proportional to the decrease in the heating value of biodiesel (Lapuerta et al., 2008). Brake specific energy consumption (bsec) or brake thermal efficiency (the inverse of bsec), are more adequate parameters than the break specific fuel consumption (bsfc) for comparing fuels and for evaluating the engine capability to be fuelled with biodiesel and biodiesel blends (Cardone et al., 2002). Combustion efficiency remained constant using either biodiesel or diesel fuel (Dorado et al., 2003b). Several studies (Dorado et al., 2003a; Pramanik, 2003; Usta, 2005; Ozgunay et al.,2007) which have previously carried out performance tests with biodiesel fuels produced from different resources, stated that biodiesel shows slightly lower performance values in comparison with petroleum diesel fuel performance. Kegl (2008, 2006) reported that because of the lower heating value of biodiesel fuel, the engine effective power is reduced by about $5 \%$ and the specific fuel consumption is increased by about $10 \%$, whereas the thermal efficiency is practically the same for both fuels. The temperatures of exhaust gases as well as the in-cylinder pressures were lower than those obtained with petroleum diesel. Agarwal and Agarwal (2007) observed significant improvement in engine performance and emission characteristics for the biodiesel-fuelled engine compared to diesel fuelled engine. Thermal efficiency of the engine improved, brake specific energy consumption reduced and a considerable reduction in the exhaust smoke opacity was observed.

The performance of engines fueled with biodiesel produced from waste vegetable oil was extensively covered in the literature (Dorado, 2003a; Tashtoush et al., 2003; Volmajer and Kegl, 2003; Najafi et al., 2007; Lapuerta et al., 2008; Meng et al., 2008; Refaat et al., 2008b; Utlu and Kocak, 2008; Ghobadian et al., 2009)

Lapuerta et al. (2008) tested two different biodiesel fuels, obtained from waste cooking oils with different previous uses in a diesel commercial engine either pure or in $30 \%$ and $70 \% \mathrm{v} / \mathrm{v}$ blends with a reference diesel fuel. The main objective of their work was to study the 
effect of biodiesel blends on particulate emissions, measured in terms of mass, optical effect (smoke opacity) and size distributions. A sharp decrease was observed in both smoke and particulate matter emissions as the biodiesel concentration was increased. The mean particle size was also reduced with the biodiesel concentration, but no significant increases were found in the range of the smallest particles. They concluded that compared to petroleum diesel, the engine efficiency is not significantly affected by using biodiesel. However, an increase in fuel consumption is observed. This increase is proportional to the decrease in the heating value of biodiesel.

Refaat et al. (2008b) found that the difference in performance between microwave-enhanced biodiesel and petroleum diesel was not statistically significant; a slight increase in SFC was detected with biodiesel, no significant differences were observed in brake thermal efficiency and the combustion efficiency remained constant using either microwave-enhanced biodiesel or Diesel fuel.

Najafi et al. (2007) noticed that by adding $20 \%$ of waste vegetable oil methyl ester to petrodiesel fuel the maximum power and torque increased by $2.7 \%$ and 2.9 $\%$, respectively (Najafi et al., 2007). The same results were reconfirmed in a succeeding study by the authors (Ghobadian et al., 2009). Utlu and Kocak (2008) reported that although the maximum power values of both Diesel fuel and waste frying oil biodiesel are very close, yet, since waste frying oil biodiesel (WFOME) has a lower heating value, higher density and viscosity, WFOME's specific fuel consumption is increased as $14.34 \%$ as shown in Fig. 14.

\section{Exhaust emissions tests of wvo-based biodiesel}

Initially, environmentally related research concentrated on regulated exhaust gas emissions (carbon monoxide, $\mathrm{NO}_{\mathrm{x}}$ and particulate matter) and it was recognized that there was a substantial reduction in these emissions, with the exception of $\mathrm{NO}_{\mathrm{x}}$ sometimes, when compared with the use of petroleum diesel fuel with no real penalties in terms of fuel consumption or engine performance. More recently, additional information on exhaust emissions with potential environmental and health importance has been studied by the characterization of unregulated exhaust emissions (Cardone et al., 2002).

Biodiesel possesses several distinct advantages over petro-diesel regarding exhaust emissions (Kegl, 2008).
Compared to mineral diesel, biodiesel generally causes a decrease of unburned $\mathrm{HC}, \mathrm{CO}$ and PM emissions and an increase of $\mathrm{NO}_{\mathrm{x}}$ emission (Tat et al., 2007). The actual results, however, vary significantly in dependence on the used fuel, employed engine, and engine operating regimes (Kegl, 2006). Ramadhas et al. (2005) have found a significant decline in CO emission values with increasing ratios of the biodiesel to petro-diesel. Results obtained by Murillo et al. (2007) revealed that the use of biodiesel resulted in lower emissions of CO (up to $12 \%$ ) with an increase in emissions of $\mathrm{NO}_{x}$ (up to $20 \%$, except in one case which presented a slight reduction). Kegl (2008, 2006) indicated that, using biodiesel, harmful emissions ( $\mathrm{NO}_{\mathrm{x}}, \mathrm{CO}$, smoke and $\left.\mathrm{HC}\right)$ can be reduced to some extent by adjusting the injection pump timing properly. Numerous reports in the literature deal with the study of exhaust emissions from engines fueled with biodiesel produced from waste vegetable (Dorado, 2003a; Tashtoush et al., 2003; Sudhir et al., 2007; Lapuerta et al., 2008; Meng et al., 2008; Refaat et al., 2008b; Utlu and Kocak, 2008; Ghobadian et al., 2009).

Lapuerta et al. (2008) found that by using biodiesel the soot and particulate matter emissions, as well as the particle number concentration, decreased sharply, mainly due to the oxygen content of the biodiesel, which improve the oxygen availability in rich-zone flames in the combustion chamber. When compared with petroleum diesel fuel, biodiesel emissions contain less soot and a greater fraction of the particulate was soluble. The analysis and speciation of the soluble organic fraction of biodiesel particulate suggest that the carcinogenic potential of the biodiesel emissions is probably lower than that of petroleum diesel (Cardone et al., 2002).

Studies on waste vegetable oils include waste olive oil by Dorado et al. (2003a; 2003b) revealed that the use of biodiesel resulted in lower emissions of CO (up to $58.9 \%$ ), $\mathrm{CO}_{2}$ (up to $8.6 \%$, excepting a case which presented a $7.4 \%$ increase), NO (up to $37.5 \%$ ) and $\mathrm{SO}_{2}$ (up to $57.7 \%$ ), with increase in emissions of $\mathrm{NO}_{2}$ (up to $81 \%$, excepting a case which presented a slight reduction). Biodiesel also presented a slight increase in brake-specific fuel consumption (lower than $8.5 \%$ ) that may be tolerated due to the exhaust emission benefits. Combustion efficiency remained constant using either biodiesel or Diesel fuel.

Refaat et al. (2008b) found that evaluation of the data relating to emission values indicated that, despite the small increase in $\mathrm{NO}_{\mathrm{x}}$ emissions, decreases in 
$\mathrm{CO}, \mathrm{NO}$ and $\mathrm{NO}_{2}$ emissions as a result of firing biodiesel were found to be statistically important compared to the emissions when burning diesel. The authors pointed out that although the results of the power tests of biodiesel are similar to petroleum diesel fuel performance values, a slight increase in SFC was detected with biodiesel. The slight increase in brakespecific fuel consumption (lower than $8.5 \%$ ) observed with biodiesel may be tolerated due to the exhaust emission benefits.

Ghobadian et al. (2009) confirmed that the concentration of the $\mathrm{CO}$ and $\mathrm{HC}$ emissions were significantly decreased when biodiesel was used. Utlu and Kocak (2008) showed that the amount of emission such as $\mathrm{CO}, \mathrm{CO} 2, \mathrm{NOx}$ and smoke darkness of waste frying oils are less than No. 2 diesel fuel (Fig. 15).

Exhaust emissions and performance tests with biodiesel fuels derived from used cooking oils have shown that this kind of biodiesel exhibit properties similar to that of biodiesel derived from "classical" vegetable oil feedstock.

\section{CONCLUSION}

While transesterification is well-established and becoming increasingly important, there remains considerable inefficiencies in existing transesterifica tion processes. There is an imperative need to improve the existing biodiesel production methods from both economic and environmental viewpoints and to investigate alternative and innovative production processes. The identification of some key parameters (acid value and FFA content, moisture content, viscosity and fatty acid profile of the used oil) is a prerequisite for determining the viability of the vegetable oil transesterification process and is essential to identify the right processes that can be performed to achieve best results with the yield and purity of the produced biodiesel.

It is evident, from the literature reviewed, that methanol has been reported to give the best result in terms of biodiesel yield and byproduct recovery. The optimum reaction conditions for base-catalyzed transesterifica- tion using methanol (methanolysis) involve using the alcohol in excess of stoichiometric proportion (preferably $100 \%$ excess) and using $\mathrm{KOH}$ or $\mathrm{NaOH}$ as a catalyst in a concentration of $1 \%$ of the weight of the oil. The temperature positively influences the biodiesel yield nearly up to about the boiling point of the alcohol (usually $60-65^{\circ} \mathrm{C}$ ) if other parameters are kept unchanged. Most investigators have observed an optimum reaction time around one hour; however, excess residence time can negatively influence the biodiesel production by favoring the backward reaction (hydrolysis of esters) which results in a reduction of product yield.

Acid catalysts show better adaptability to FFAs than base catalysts and can catalyze esterification and transesterification simultaneously. However, it suffers some shortcomings such as high alcohol to oil molar ratio, high catalyst concentration and high temperature. Also, the reaction is relatively slow and the catalyst ends up in the by-products causing serious separation

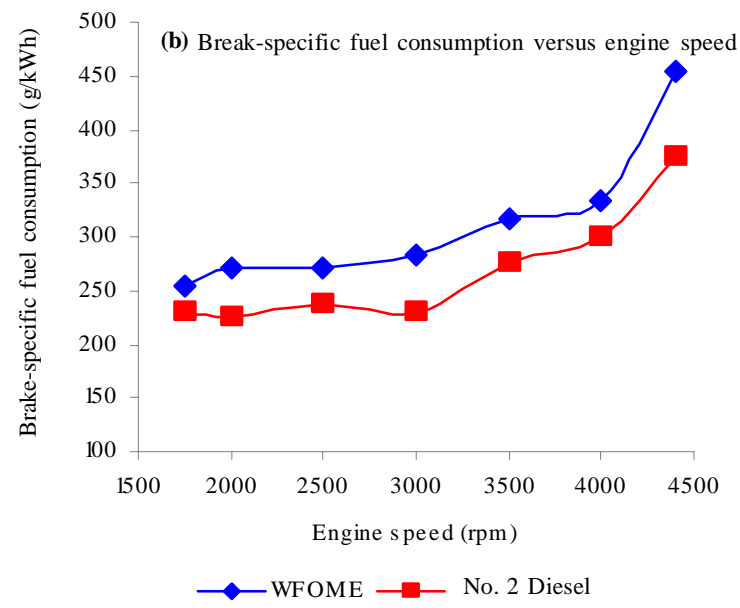

Fig. 14: Performance Tests for engines fueled by WVO-based Biodiesel (Utlu and Kocak, 2008) 

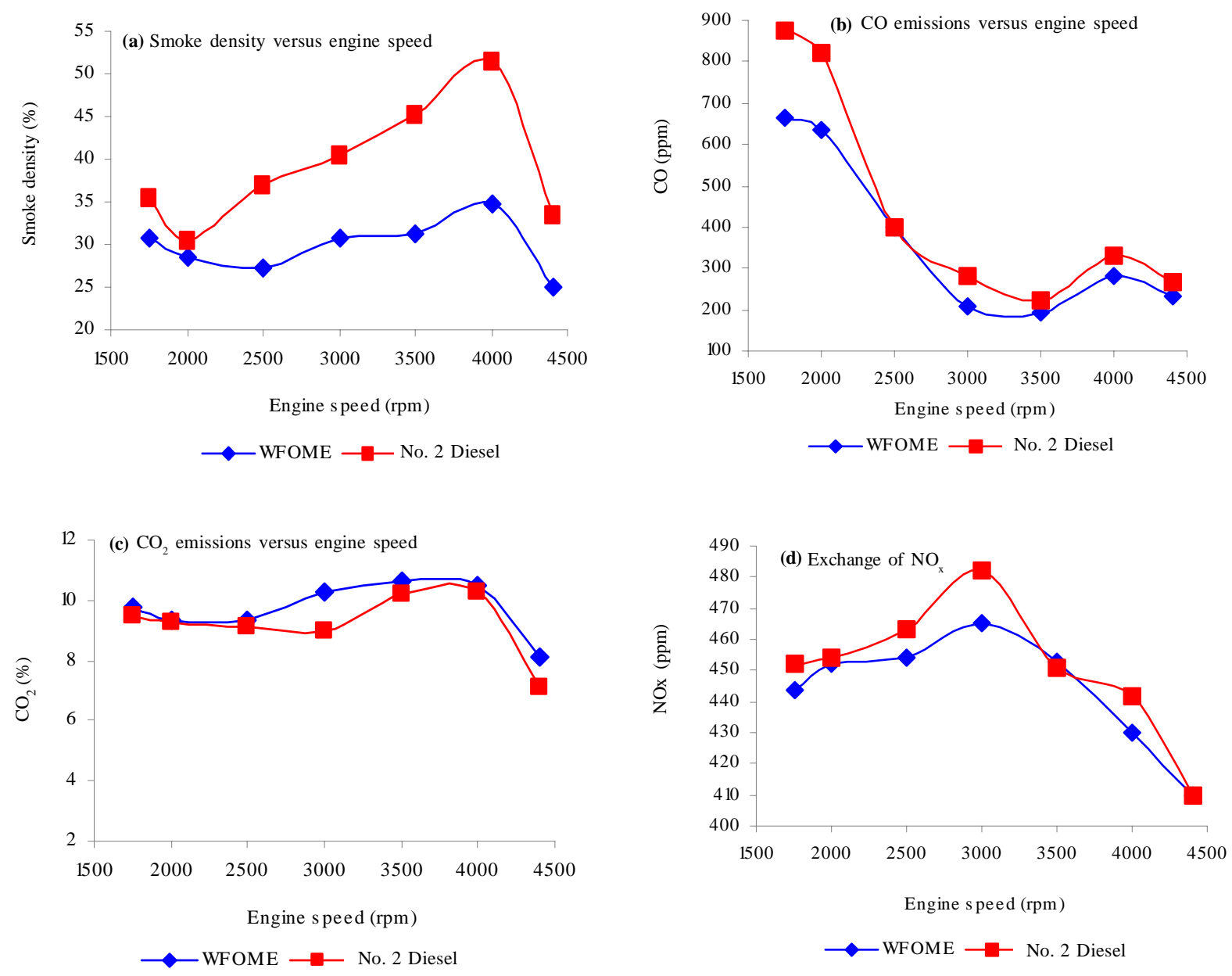

Fig. 15: Exhaust emissions from WVO-based biodiesel (Utlu and Kocak, 2008)

problems. All these factors in addition to the serious environmental and corrosion-related problems limit their use. Despite its advantages, the two-stage method also faces the problem of catalyst removal in both stages. The problem of catalyst removal in the first stage can be avoided by neutralizing the acid catalyst, using extra alkaline catalyst in the second stage. However, the use of extra catalyst will increase the cost of biodiesel. The use of solid acid catalysts can offer many advantages as: they are insensitive to FFA content, they can perform esterification and transesterification simultaneously, they can be easily separated from the products, they show good stability and can be recycled and they are environmentally friendly. However, the process deserves to be further investigated. Positive results should be expected if more research efforts are directed to this field.
The enzymatic approach is environmentally friendly, considered a "green reaction", however, the cost of the final enzymatic product remains a hurdle compared to the cheaper alternative of using chemical catalysis. The process needs to be explored for industrial production of biodiesel and more work has to be done to justify its industrial application in the future. Also, the supercritical technology has been shown to be a promising technique for future large-scale biodiesel production especially from waste oil. However, the supercritical technology suffers from certain drawbacks including the harsh operation environment and high cost.

Despite the prominent advantages the ultrasonication and microwave technologies offer compared to the conventional base-catalyzed transesterification, yet, these emerging technology 
needs to be further investigated for possible scale-up for industrial application.

Exhaust emissions and performance tests with biodiesel fuels derived from used cooking oils have shown that this kind of biodiesel exhibit properties similar to that of biodiesel derived from "classical" vegetable oil feedstock. The new process technologies developed during the last years made it possible to produce biodiesel from recycled frying oils comparable in quality to that of virgin vegetable oil biodiesel with an added attractive advantage of being lower in price. Thus, biodiesel produced from recycled frying oils has the same possibilities to be utilized.

\section{REFERENCES}

Agarwal, D.; Agarwal, A. K., (2007). Performance and emissions characteristics of Jatropha oil (preheated and blends) in a direct injection compression ignition engine. Appl. Therm. Eng., 27 (13), 2314-2323 (10 pages).

Akoh, C. C.; Chang, S. W.; Lee, G. C.; Shaw, J. F., (2007). Enzymatic approach to biodiesel production. J. Agr. Food Chem., 55 (22), 8995-9005 (11 pages).

Alcantara, R.; Amores, J.; Canoira, L.; Fidalgo, E.; Franco, M. J.; Navarro, A., (2000). Catalytic production of biodiesel from soy-bean oil, used frying oil and tallow. Biomass Bioenerg., 18 (6), 515-527 (3 pages).

Al-Widyan, M. I.; Al-Shyoukh, A. O., (2002). Experimental evaluation of the transesterification of waste palm oil into biodiesel. Bioresour. Tech., 85 (3), 253-256 (4 pages).

Antczak, M. S.; Kubiak, A.; Antczak, T.; Bielecki, S., (2009). Enzymatic biodiesel synthesis - Key factors affecting efficiency of the process. Renew. Energ., 34 (5), 11851194 (10 pages).

Barnard, T. M.; Leadbeater, N. E.; Boucher, M. B.; Stencel, L. M.; Wilhite, B. A., (2007). Continuous-Flow preparation of biodiesel using microwave heating. Energ. Fuel., 21 (3), 1777-1781 (10 pages).

Bournay, L.; Casanave, D.; Delfort, B.; Hillion, G.; Chodorge, J. A., (2005). New heterogeneous process for biodiesel production: A way to improve the quality and the value of the crude glycerin produced by biodiesel plants. Catal. Today, 106 (1-4), 190-192 (3 pages).

Canakci, M., (2007). The potential of restaurant waste lipids as biodiesel feedstocks. Bioresour. Tech., 98 (1), 183-190 (8 pages).

Canakci, M.; van Gerpen, J. H., (2001). A pilot plant to produce biodiesel from high free fatty acid feedstocks. American Society of Agricultural Engineers, ASAE Annual International Meeting, Sacramento, California, USA, July 30-August 1, 2001, Paper Number: 016049.

Cao, F.; Chen, Y.; Zhai, F.; Li, J.; Wang, J.; Wang, X.; Wang, S.; Zhu, W., (2008). Biodiesel production from high acid value waste frying oil catalyzed by superacid heteropolyacid. Biotech. Bioengin., 101 (1), 93-100 (8 pages).

Cao, W. L.; Han, H. W.; Zhang, J. C., (2005). Preparation of biodiesel from soybean oil using supercritical methanol and co-solvent. Fuel, 84 (4), 347-351 (5 pages).
Cardone, M.; Prati, M. V.; Rocco, V.; Seggiani, M.; Senatore, A.; Vitolo, S., (2002). Brassica carinata as an Alternative Oil Crop for the Production of Biodiesel in Italy: Engine Performance and Regulated and Unregulated Exhaust Emissions. Environ. Sci. Tech., 36 (21), 4656-4662 (7 pages).

Cayli, G.; Küsefoglu, S., (2008). Increased yields in biodiesel production from used cooking oils by a two step process: Comparison with one step process by using TGA. Fuel Proc. Tech., 89 (2), 118-122 (5 pages).

Cerveró, J. M.; Coca, J.; Luque, S., (2008). Production of biodiesel from vegetable oils. Grasas Y Aceites. Int. J. Fata Oils, 59 (1), 76-83 (8 pages).

Chai, F.; Cao, F.; Zhai, F.; Chen, Y., Wang, X.; Su, Z., (2007). Transesterification of vegetable oil to biodiesel using heteropolyacid solid catalyst. Adv. Synth. Catal., 349 (7), 1057-1065 (8 pages).

Chen, G.; Ying, M.; Li, W., (2006). Enzymatic conversion of waste cooking oils into alternative fuel - Biodiesel. Appl. Biochem. Biotech., 132 (1-3), 911-921 (11 pages).

Chhetri, A. B.; Watts, K. C.; Islam, M. R., (2008). Waste cooking oil as an alternate feedstock for biodiesel production. Energies, 1 (1), 3-18 (16 pages).

Colucci, J. A.; Borrero, E. E.; Alape, F., (2005). Biodiesel from an alkaline transesterification reaction of soybean oil using ultrasonic mixing. J. Am. Oil Chem. Soc., 82 (7), 525-530 (6 pages).

Cvengros, J. J.; Cvengrosová, Z., (2004). Used frying oils and fats and their utilization in the production of methyl esters of higher fatty acids. Biomass Bioenerg., 27 (2), 173-181 (9 pages).

De Paola, M. G.; Ricca, E.; Calabro, V.; Curcio, S.; Iorio, G. (2009). Factor analysis of transesterification reaction of waste oil for biodiesel production. Bioresour. Tech., 100 (21), 5126-5131 (6 pages).

Demirbas, A., (2007). Biodiesel from sunflower oil in supercritical methanol with calcium oxide. Energ. Convers. Manage., 48 (3), 937-941 (5 pages).

Demirbas, A., (2009). Biodiesel from waste cooking oil via base-catalytic and supercritical methanol transesterification. Energ. Convers. Manage., 50 (4), 923927 (5 pages).

Di Serio, M.; Tesser, R.; Pengmei, L.; Santacesaria, E., (2008). Heterogeneous catalysts for biodiesel production. Energ. Fuel., 22 (1), 207-217 (11 pages).

Dias, J. M.; Alvim-Ferraz, M. C. M.; Almeida, M. F., (2008). Comparison of different homogeneous alkali catalysts during transesterification of waste and virgin oils and evaluation of biodiesel quality. Fuel, 87 (17-18), 35723578 ( 7 pages).

Dorado, M. P.; Ballesteros, E.; Arnal, J. M.; Gomez, J.; Lopez, F. J., (2003a). Testing waste olive oil methyl ester as a fuel in a diesel engine. Energ. Fuel., 17 (6), 1560-1565 (6 pages).

Dorado, M. P.; Ballesteros, E.; Arnal, J. M.; Gomez, J.; Lopez, F. J., (2003b). Exhaust emissions from a diesel engine fueled with transesterified waste olive oil. Fuel, 82 (11), 13111315 (5 pages).

Dorado, M. P.; Ballesteros, E.; Mittelbach, M.; Lopez, F. J., (2004). Kinetic parameters affecting the alkali-catalyzed 
transesterification process of used olive oil. Energ. Fuel., 18 (5), 1457-1462 (6 pages).

Dorado, M. P.; Cruz, F.; Palomar, J. M.; Lopez, F. J., (2006). An approach to the economics of two vegetable oil-based biofuels in Spain. Renew. Energ., 31 (8), 1231-1237 (7 pages).

El Sheltawy, S. T.; Refaat, A. A., (2008). Using ultrasonication for fast production of biodiesel from waste vegetable oil in

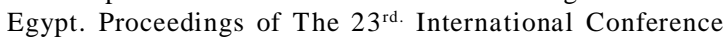
on Solid Waste Technology and Management, March 30 April 2, 2008, Philadelphia, USA. 1288-1297.

El Sheltawy, S. T.; Refaat, A. A., (2009). A recommended holistic policy framework for vegetable oil waste management in Egypt. Proceedings of the $24^{\text {th }}$ International conference on solid waste technology and management (ICSW’09), Philadelphia, USA, March 15 - 18, 560-577.

Encinar, J. M.; Gonzalez, J. F.; Rodriguez-Reinares, A., (2005). Biodiesel from used frying oil. Variables affecting the yields and characteristics of the biodiesel. Ind. Eng. Chem. Res., 44 (15), 5491-5499 (9 pages).

Encinar, J. M.; Juan, F.; Gonzalez, J. F.; Rodriguez-Reinares, A., (2007). Ethanolysis of used frying oils: Biodiesel preparation and Characterization. Fuel Process. Tech., 88 (5), 513-522 (10 pages).

Felizardo, P.; Correia, M. J.; Raposo, I.; Mendes, J. F.; Berkemeier, R.; Bordado J. M., (2006). Production of biodiesel from waste frying oils. Waste Manage., 26 (5), 487-494 (8 pages).

Fini, A.; Breccia, A., (1999). Chemistry by microwaves. Pure Appl. Chem., 71 (4), 573-579 (7 pages).

Freedman, B.; Butterfield, R. O.; Pryde, E. H., (1986). Transesterification kinetics of soybean oil. J. Am. Oil Chem. Soc., 63 (10), 1375-1380 (6 pages).

Freedman, B.; Pryde, E. H.; Mounts, T. L., (1984). Variables affecting the yields of fatty esters from transesterified vegetable oils. J. Am. Oil Chem. Soc., 61 (10), 1638-1643 (6 pages).

Furuta, S.; Matsuhashi, H.; Arata, K., (2004). Biodiesel fuel production with solid superacid catalysis in fixed bed reactor under atmospheric pressure. Catal. Commun., 5 (12), 721 723 (4 pages).

Ghobadian, B.; Rahimi, H.; Nikbakht, A. M.; Najafi, G.; Yusaf, T. F., (2009). Diesel engine performance and exhaust emission analysis using waste cooking biodiesel fuel with an artificial neural network. Renew. Energ., 34 (4), 976982 (7 pages).

Gupta, A.; Sharma, S. K.; Pal Toor, A., (2007). Production of biodiesel from waste soybean oil. J. Petrotech Soc., IV (1), 40-45 (6 pages).

Haas, M. J.; McAloon, A. J.; Yee, W. C.; Foglia, T. A., (2006). A process model to estimate biodiesel production costs. Bioresour. Tech., 97 (4), 671-678 (8 pages).

Han, H. W.; Cao, W. L.; Zhang J. C., (2005). Preparation of biodiesel from soybean oil using supercritical methanol and $\mathrm{CO}_{2}$ as co-solvent. Process Biochem., 40 (9), 31483151 (4 pages).

Hancsók, J.; Kovács, F.; Krár, M., (2004). Production of vegetable oil fatty acid methyl esters from used frying oil by combined acidic/alkali transesterification. Petrol. Coal., 46 (3), 36-44 (9 pages).
Hanh, H. D.; Dong, N. T.; Starvarache, C.; Okitsu, K.; Maeda, Y.; Nishimura, R., (2008). Methanolysis of triolein by low frequency ultrasonic irradiation. Energ. Convers. Manage., 49 (2), 276-280 (5 pages).

Hayes, B. L. (2004). Recent advances in microwave-assisted synthesis. Aldrichimica Acta., 37 (2), 66-77 (12 pages).

Hernando, J.; Leton, P.; Matia, M. P.; Novella, J. L.; AlvarezBuilla, J., (2007). Biodiesel and FAME synthesis assisted by microwaves: Homogeneous batch and flow processes. Fuel, 86 (10-11), 1641-1644 (6 pages).

Hill, J.; Nelson, E.; Tilman, D.; Polasky, S.; Tiffany, D., (2006). Environmental, economic, and energetic costs and benefits of biodiesel and ethanol biofuels. Proceedings of the National Academy of Science of the United States of America (PNAS), 103 (30), 11206-11210 (5 pages).

Issariyakul, T.; Kulkarni, M. G.; Dalai, A. K.; Bakhshi, N. N. (2007). Production of biodiesel from waste fryer grease using mixed methanol/ethanol system. Fuel Process Tech., 88 (5), 429-436 (8 pages).

Jacobson, K.; Gopinath, R.; Meher, C.; Dalai, A. K., (2008). Solid acid catalyzed biodiesel production from waste cooking oil. Appl. Catal. B-Environ., 85 (1-2), 86-91 (6 pages).

Jitputti, J; Kitiyanan, B.; Rangsunvigit, P.; Bunyakiat, K.; Attanatho, L.; Jenvanitpanjakul, P. (2006). Transesterification of crude palm kernel oil and crude coconut oil by different solid catalysts. Chem. Eng. J., 116 (1), 61-66 (6 pages).

Kegl, B., (2006). Experimental investigation of optimal timing of the diesel engine injection pump using biodiesel fuel. Energ. Fuel., 20 (4), 1460-1470 (11 pages).

Kegl, B., (2008). Effects of biodiesel on emissions of a bus diesel engine. Bioresour. Tech., 99 (4), 863-873 (11 pages).

Kelkar, M. A.; Gogate, P. R.; Pandit, A. B., (2008). Intensification of esterification of acids for synthesis of biodiesel using acoustic and hydrodynamic cavitation. Ultrason. Sonochem., 15 (3), 188-194 (7 pages).

Kiss, A. A.; Dimian, A. C.; Rothenberg, G., (2006). Solid acid catalysts for biodiesel production-towards sustainable energy. Adv. Synth. Catal., 348 (1-2), 75-81 (7 pages).

Knothe, G.; Steidley, K. R., (2009). A comparison of used cooking oils: A very heterogeneous feedstock for biodiesel. Bioresour. Tech., 100 (23), 5796-5801 (6 pages).

Koh, T. S.; Chung, K. H., (2008). Production of biodiesel from waste frying oil by transesterification on zeolite catalysts with different acidity. J. Korean Ind. Eng. Chem., 19 (2), 214-221 (8 pages).

Kulkarni, M. G.; Dalai, A. K., (2006). Waste cooking oil - an economical source for biodiesel: A review. Ind. Eng. Chem. Res., 45 (9), 2901-2913 (13 pages).

Kusdiana, D.; Saka, S., (2001). Kinetics of transesterification in rapeseed oil to biodiesel fuel as treated in supercritical methanol. Fuel, 80 (5), 693-698 (6 pages).

Lam, M. K.; Tan, K. T.; Lee, K. T.; Mohamed, A. R., (2009). Malaysian palm oil: Surviving the food versus fuel debate for a sustainable future. Renew. Sust. Energ. Rev., 13 (6-7), 1456-1464 (9 pages).

Lapuerta, M.; Rodriguez-Fernandez, J.; Agudelo, J. R., (2008). Diesel particulate emissions from used cooking oil biodiesel. Bioresour. Tech., 99 (4), 731-740 (10 pages). 
Leadbeater, N. E.; Stencel, L. M., (2006). Fast, easy preparation of biodiesel using microwave heating. Energ. Fuel., 20 (5), 2281-2283 (3 pages).

Lee, K. T.; Foglia, T. A.; Chang, K. S., (2002). Production of alkyl ester as biodiesel from fractionated lard and restaurant grease. J. Am. Oil Chem. Soc., 79 (2), 191-195 (5 pages).

Leung, D. Y. C.; Guo, Y., (2006). Transesterification of neat and used frying oil: Optimization for biodiesel production. Fuel Process Tech., 87 (10), 883-890 (8 pages).

Li, J.; Wang, X.; Zhu, W.; Cao, F., (2009). $\mathrm{Zn}_{1.2} \mathrm{H}_{0.6} \mathrm{PW}_{12} \mathrm{O}_{40}$ Nanotubes with double acid sites as heterogeneous catalysts for the production of biodiesel from waste cooking oil. ChemSusChem., 2 (2), 177-183 (7 pages).

Li, N. W.; Zong, M. H.; Wu, H., (2009). Highly efficient transformation of waste oil to biodiesel by immobilized lipase from Penicillium expansum. Process Biochem., 44 (6), 685-688 (4 pages).

Lidstrom, P.; Tierney, J.; Wathey, B.; Westman, J., (2001). Microwave assisted organic synthesis-a review. Tetrahedron, 57 (45), 9225-9283 (59 pages).

Lima, S. M.; Izida, T.; Figueiredo, M. S.; Andrade, L. H. C.; Del Ré, P. V.; Jorge, N.; Buba, E.; Aristone, F., (2008). Analysis of biodiesel and frying vegetable oils by means of FTIR photoacoustic spectroscopy. Eur. Physic. J. Special Topics, 153 (1), 535-537 (3 pages).

Lopez, D. E.; Goodwin, J. G.; Bruce, D. A.; Furuta, S., (2008). Esterification and transesterification using modified-zirconia catalysts. Appl. Catal. A-Gen., 339 (1), 76-83 (8 pages).

Lotero, E.; Liu, Y.; Lopez, D. E.; Suwannakarn, K.; Bruce, D. A.; Goodwin, Jr., J. G., (2005). Synthesis of biodiesel via acid catalysis. Ind. Eng. Chem. Res., 44 (14), 5353-5363 (11 pages).

Lou, W. Y.; Zong, M. H.; Duan, Z. Q., (2008). Efficient production of biodiesel from high free fatty acid-containing waste oils using various carbohydrate-derived solid acid catalysts. Bioresour. Tech., 99 (18), 8752-8758 (7 pages).

Ma, F.; Hanna, M. A., (1999). Biodiesel production: A review. Bioresour. Tech., 70 (1), 1-15 (15 pages).

Maceiras, R.; Vega, M.; Costa, C.; Ramos, P.; Marquez, M. C., (2009). Effect of methanol content on enzymatic production of biodiesel from waste frying oil. Fuel, 88 (11), 2130-2134 (5 pages).

Maniak, B.; Szmigielski, M.; Piekarski, W.; Markowska, A., (2009). Physicochemical changes of post-frying sunflower oil. Int. Agrophysic., 23 (3), 243-248 (6 pages).

Marchetti, J. M.; Miguel, V. U.; Errazu, A. F., (2008). Technoeconomic study of different alternatives for biodiesel production. Fuel Process Tech., 89 (8), 740-748 (9 pages).

Marmesat, S.; Velasco, J.; Márquez-Ruiz, G.; Dobarganes, M. C., (2007a). A rapid method for determination of polar compounds in used frying fats and oils. Grasas Aceites. 58 (2), 179-184 (6 pages).

Marmesat, S.; Rodrigues, E.; Velasco, J.; Dobarganes, C., (2007b). Quality of used frying fats and oils: Comparison of rapid tests based on chemical and physical oil properties. Int. J. Food Sci. Tech., 42 (5), 601-608 (8 pages).

Mazzocchia, C.; Modica, G.; Nannicini, R.; Kaddouri, A., (2004). Fatty acid methyl esters synthesis from triglycerides over heterogeneous catalysts in the presence of microwaves. Cr. Chim., 7 (6-7), 601-605 (5 pages).
Meher, L. C.; Sagar, D. V.; Naik, S. N., (2006). Technical aspects of biodiesel production by transesterification-a review. Renew. Sust. Energ. Rev., 10 (3), 248-268 (21 pages).

Meng, X.; Chen, G.; Wang, Y., (2008). Biodiesel production from waste cooking oil via alkali catalyst and its engine test. Fuel Process Tech., 89 (9), $851-857$ (7 pages).

Metzger, J. O., (2009). Fats and oils as renewable feedstock for chemistry. Eur. J. Lipid Sci. Tech., 111 (9), 865-876 (12 pages).

Mingos, D. M. P.; Baghurst, D. R., (1991). Applications of microwave dielectric heating effects to synthetic problems in chemistry. Chem. Soc. Rev., 20 (1), 1-47 (47 pages).

Murillo, S.; Miguez, J. L.; Porteiro, J.; Granada, E.; Moran, J. C., (2007). Performance and exhaust emissions in the use of biodiesel in outboard diesel engines. Fuel, 86 (12-13), 1765-1771 (6 pages).

Najafi, G.; Ghobadian, B.; Yusaf, T. F.; Rahimi, H., (2007). Combustion analysis of a CI engine performance using waste cooking biodiesel fuel with an artificial neural network aid. Am. J. Appl. Sci., 4 (10), 759-767 (9 pages).

Noureddini, H.; Zhu, D., (1997). Kinetics of transesterification of soybean oil. J. Am. Oil Chem. Soc., 74 (11), 1457-1463 (7 pages).

Om Tapanes, N. C.; Gomes Aranda, D. A.; de Mesquita Carneiro, J. W.; Ceva Antunes, O. A., (2008). Transesterification of Jatropha curcas oil glycerides: Theoretical and experimental studies of biodiesel reaction. Fuel, 87 (10-11), 2286-2295 (10 pages).

Ozbay, N.; Oktar, N.; Tapan, N. A., (2008). Esterification of free fatty acids in waste cooking oils (WCO): Role of ion exchange resins. Fuel, 87 (11-12), 1789-1798 (10 pages).

Ozgunay, H.; Colak, S.; Zengin, G.; Sari, O.; Sarikahya, H.; Yuceer, L., (2007). Performance and emission study of biodiesel from leather industry pre-fleshings. Waste Manage., 27 (12), 1897-1901 (5 pages).

Peng, B. X.; Shu, Q.; Wang, J. F.; Wang, G. R.; Wang, D. Z.; Han, M. H., (2008). Biodiesel production from waste oil feedstocks by solid acid catalysis. Process Saf. Environ. Protect., 86 (6), 441-447 (7 pages).

Perreux, L.; Loupy, A., (2001). A tentative rationalization of microwave effects in organic synthesis according to the reaction medium, and mechanistic considerations. Tetrahedron, 57 (45), 9199-9223 (25 pages).

Pimentel, D.; Marklein, A.; Toth, M. A.; Karpoff, M. N.; Paul, G. S.; McCormack, R.; Kyriazis, J.; Krueger, T., (2009). Food versus biofuels: Environmental and economic costs. Hum. Eco., 37 (1), 1-12 (13 pages).

Pinto, A. C.; Guarieiro, L. N.; Rezende, M. J.; Ribeiro, N. M.; Torres, E. A.; Lopes, W. A.; Pereira, P. A.; Andrade, J. B. (2005). Biodiesel: An overview. J. Brazil. Chem. Soc., 16 (6B), 1313-1330 (18 pages).

Pramanik, K., (2003). Properties and use of jatropha curcas oil and diesel fuel blends in compression ignition engine. Renew. Energ., 28 (2), 239-248 (10 pages).

Predojevic, Z. J., (2008). The production of biodiesel from waste frying oils: A comparison of different purification steps. Fuel, 87 (17-18), 3522-3528 (7 pages).

Ramadhas, A. S., Muraleedharan, C.; Jayaraj, S., (2005). Performance and emission evaluation of a diesel engine fueled with methyl esthers of rubber seed oil. Renew. Energ., 30 (12), 1789-1800 (12 pages). 
Refaat, A. A., (2009). Correlation between the chemical structure of biodiesel and its physical properties. Int. J. Environ. Sci. Tech., 6 (4), 677-694 (18 pages).

Refaat, A. A.; Attia, N. K.; Sibak, H. A.; El Sheltawy, S. T.; El Diwani, G. I., (2008a). Production optimization and quality assessment of biodiesel from waste vegetable oil. Int. J. Environ. Sci. Tech., 5 (1), 75-82 (8 pages).

Refaat, A. A.; El Sheltawy, S. T., (2008). Comparing three options for biodiesel production from waste vegetable oil. WIT Transactions on Ecology and the Environment, Waste Management and the Environment IV, Vol. 109, WIT Press, $133-140$

Refaat, A. A.; El Sheltawy, S. T.; Sadek, K. U., (2008b). Optimum reaction time, performance and exhaust emissions of biodiesel produced by microwave irradiation. Int. J. Environ. Sci. Tech., 5 (3), 315-322 (8 pages).

Rodrigues Machado, E.; Marmesat, S.; Abrantes, S. 1.; Dobarganes, C., (2007). Uncontrolled variables in frying studies: differences in repeatability between thermoxidation and frying experiments. Grasas Aceites., 58 (3), 283-288 (6 pages).

Ruiz-Méndez, M. V.; Marmesat, S.; Liotta, A.; Dobarganes, M. C., (2008). Analysis of used frying fats for the production of biodiesel. Grasas Aceites., 59 (1), 45-50 (6 pages).

Rutz, D.; Janssen, R., (2008). Biofuel technology handbook. $2^{\text {nd. Version, }}$ WIP Renewable Energies, Munchen, Germany.

Saifuddin, N.; Chua, K. H., (2004). Production of ethyl ester (Biodiesel) from used frying oil: Optimization of transesterification process using microwave irradiation. Malays. J. Chem., 6 (1), 77- 82 (6 pages).

Schuchardt, U.; Serchelia, R.; Vargas, R. M., (1998). Transesterification of vegetable oils: a review. J. Brazil. Chem. Soc., 9 (1), 199-210 (12 pages).

Shimada, Y.; Watanabe, Y.; Sugihara, A.; Tominaga, Y., (2002). Enzymatic alcoholysis for biodiesel fuel production and application of the reaction to oil processing. J. Molecul. Catal. B: Enzymatic, 17 (3-5), 133-142 (10 pages).

Singh, A.; He, B.; Thompson, J.; van Gerpen, J., (2006). Process optimization of biodiesel production using different alkaline catalysts. Appl. Eng. Agr., 22 (4), 597-600 (4 pages).

Singh, A. K.; Fernando, S. D., (2006). Catalyzed fasttransesterification of soybean oil using ultrasonication. American Society of Agricultural Engineers, ASAE Annual Meeting, Portland, Oregon, USA, July 9-July 12, Paper number 066220 .

Sivasamy, A.; Cheah, K. Y.; Fornasiero, P.; Kemausuor, F.; Zinoviev, S.; Miertus, S., (2009). Catalytic applications in the production of biodiesel from vegetable oils. ChemSusChem, 2 (4), 278-300 (23 pages).

Srinivasan, S., (2009). The food v fuel debate: a nuanced view of incentive structures. Renew. Energ., 34 (4), 950-954 (5 pages).

Stamenkovic, O. S.; Lazic, M. L.; Todorovic, Z. B.; Veljkovic, V. B.; Skala, D. U., (2007). The effect of agitation intensity on alkali-catalyzed methanolysis of sunflower oil. Bioresour. Tech., 98 (14), 2688-2699 (12 pages).

Stavarache, C.; Vinatoru, M.; Maeda, Y., (2007a). Aspects of ultrasonically assisted transesterification of various vegetable oils with methanol. Ultrason. Sonochem., 14 (3), 380-386 (7 pages).

Stavarache, C.; Vinatoru, M.; Maeda, Y.; Bandow, H. (2007b). Ultrasonically driven continuous process for vegetable oil transesterification. Ultrason. Sonochem., 14 (4), 413-417 (5 pages).

Stavarache, C.; Vinatoru, M.; Nishimura, R.; Maeda, Y., (2005). Fatty acids methyl esters from vegetable oil by means of ultrasonic energy. Ultrasoni. Sonochem., 12 (5), 367-372 (6 pages).

Sudhir, C. V.; Sharma, N. Y.; Mohanan, P., (2007). Potential of waste cooking oil as biodiesel feedstock. Emirates J. Eng. Res., 12 (3), 69-75 (7 pages).

Supple, B.; Howard-Hildige, R.; Gonzalez-Gomez, E.; Leahy, J. J., (2002). The effect of steam treating waste cooking oil on the yield of methyl ester. J. Am. Oil Chem. Soc., 79 (2), 175-178 (4 pages).

Szmigielski, M.; Maniak, B.; Piekarski, W., (2008). Evaluation of chosen quality parameters of used frying rape oil as fuel biocomponent. Int. Agrophys., 22 (4), 361-364 (4 pages).

Tashtoush, Gh., Al-Widyan, M. I.; Al-Shyoukh, A. O., (2003). Combustion performance and emissions of ethyl ester of a waste vegetable oil in a water-cooled furnace. Appl. Therm. Eng., 23 (3), 285-293 (4 pages).

Tat, M. E.; van Gerpen, J. H.; Wang, P. S., (2007). Fuel property effects on injection timing, ignition timing, and oxides of nitrogen emissions from biodiesel-fueled engines. Am. Soc. Agr. Eng., 50 (4), 1123-1128 (6 pages).

Tehrani, S. M.; Karbassi, A. R.; Ghoddosi, J.; Monavvari, S. M.; Mirbagheri, S. A., (2009). Prediction of energy consumption and urban air pollution reduction in e-shopping adoption. J. Food, Agr. Environ. 7 (3-4), 132-137 (6 pages).

Tomasevic, A. V.; Siler-Marinkovic, S. S., (2003). Methanolysis of used frying oil. Fuel Process Tech., 81 (1), 1-6 (6 pages).

Tschakert, P.; Huber-Sannwald, E.; Ojima, D. S.; Raupach, M. R.; Schienke, E., (2008). Holistic, adaptive management of the terrestrial carbon cycle at local and regional scales. Glob. Environ. Change, 18 (1), 128-141 (14 pages).

Usta, N., (2005). Use of tobacco seed oil methyl ester in a turbocharged indirect injection diesel engine. Biomass Bioenerg., 28 (1), 77-86 (10 pages).

Utlu, Z.; Kocak, M. S., (2008). The effect of biodiesel fuel obtained from waste frying oil on direct injection diesel engine performance and exhaust emissions. Renew. Energ., 33 (8), 1936-1941 (6 pages).

van Gerpen, J. H., (2005). Biodiesel processing and production. Fuel Process Tech., 86 (10), 1097-1107 (11 pages).

van Kasteren, J. M. N.; Nisworo, A. P., (2007). A process model to estimate the cost of industrial scale biodiesel production from waste cooking oil by supercritical transesterification. Resour., Consery. Recy., 50 (4), 442458 (37 pages).

Varma, R. S., (2001). Solvent-free accelerated organic syntheses using microwaves. Pure Appl. Chem., 73 (1), 193-198 (6 pages).

Volmajer, M.; Kegl, B., (2003). Biodiesel and waste cooking oil as the alternative fuels: The injection process aspect. Fuel. Lubricants, 42 (3), 177-197 (21 pages).

Wan Omar, W. N. N.; Nordin, N.; Mohamed, M.; Amin, N. A. S., (2009). A two-step biodiesel production from waste cooking oil: Optimization of pre-treatment step. J. Appl. Sci., 9 (17), 3098-3103 (6 pages). 
Wang, Y.; Ou, S.; Liu, P.; Xue, F.; Tang, S., (2006). Comparison of two different processes to synthesize biodiesel by waste cooking oil. J. Mol. Catal. A-Chem., 252 (1-2), 107-112 (6 pages).

Warabi, Y.; Kusdiana, D.; Saka, S., (2004). Reactivity of triglycerides and fatty acids of rapeseed oil in supercritical alcohols. Bioresour. Tech., 91 (3), 283-287 (5 pages).

Watanabe, Y.; Shimada, Y.; Sugihara, A.; Tominaga, Y., (2001). Enzymatic conversion of waste edible oil to biodiesel fuel in a fixed-bed bioreactor. J. Am. Oil Chem. Soc., 78 (7), 703-707 (5 pages).

Wen, D.; Jiang, H.; Zhang, K., (2009). Supercritical fluids technology for clean biofuel production. Prog. Nat. Sci., 19 (3), 273-284 (12 pages).

West, A. H.; Posarac, D.; Ellis, N., (2008). Assessment of four biodiesel production processes using HYSYS. Plant. Bioresour. Tech. 99 (14), 6587-6601 (15 pages).

Wong, N. H.; Law, P. L.; Lai, S. H., (2007). Field tests on a grease trap effluent filter. Int. J. Environ. Sci. Tech., 4 (3), 345-350 (6 pages).

Wu, P.; Yang, Y.; Colucci, J. A.; Grulke, E. A., (2007). Effect of ultrasonication on droplet size in biodiesel mixtures. J. Am. Oil Chem. Soc., 84 (9), 877-884 (8 pages).

Yin, J. Z.; Xiao, M.; Song, J. B., (2008). Biodiesel from soybean oil in supercritical methanol with co-solvent. Energ.
Conver. Manage., 49 (5), 908-912 (5 pages).

Yuan, X.; Liu, J.; Zeng, G.; Shi, J.; Tong, J.; Huang, G., (2008). Optimization of conversion of waste rapeseed oil with high FFA to biodiesel using response surface methodology. Renew. Energ., 33 (7), 1678-1684 (7 pages).

Zhang, Y.; Dube, M. A.; McLean, D. D.; Kates, M., (2003a). Biodiesel production from waste cooking oil: 1 . Process design and technological assessment. Bioresour. Tech., 89 (1), 1-16 (16 pages).

Zhang, Y.; Dube, M. A.; McLean, D. D.; Kates, M., (2003b). Biodiesel production from waste cooking oil: 2. Economic assessment and sensitivity analysis. Bioresour. Tech., 90 (3), 229-240 (12 pages).

Zheng, S.; Kates, M.; Dube, M. A.; McLean, D. D., (2006). Acid-catalyzed production of biodiesel from waste frying oil. Biomass Bioenerg., 30 (3), 267-272 (6 pages).

Zhou, W.; Boocock, D. G. B., (2006). Phase behavior of the base-catalyzed transesterification of soybean oil. J. Am. Oil Chem. Soc., 83 (12), 1041-1045 (5 pages).

Zong, M. H.; Duan, Z. Q.; Lou, W. Y.; Smith, T. J.; Wu, H., (2007). Preparation of a sugar catalyst and its use for highly efficient production of biodiesel. Green Chem., 9 (5), 434 437 (4 pages).

\section{AUTHOR (S) BIOSKETCHES}

Refaat, A. A., B.Sc. (Hons), M.Sc., Teaching assistant, Department of Chemical Engineering, Faculty of Engineering, Cairo University,

Cairo, Egypt. Email: aarefaat@hotmail.com

How to cite this article: (Harvard style)

Refaat, A. A., (2010). Different techniques for the production of biodiesel from waste vegetable oil. Int. J. Environ. Sci. Tech., 7 (1), 183-213. 